\title{
Characteristics of Rain Integral Parameters during Tropical Convective, Transition, and Stratiform Rain at Gadanki and Its Application in Rain Retrieval
}

\author{
SAnJay Sharma, Mahen Konwar, * And Diganta Kumar SARma \\ Department of Physics, Kohima Science College, Kohima, India \\ M. C. R. KALAPUREDDY \\ Indian Institute of Tropical Meteorology, Pune, India
}

A. R. JAIN

National Physical Laboratory, New Delhi, India

(Manuscript received 16 January 2008, in final form 5 November 2008)

\begin{abstract}
In the present study the characteristics of rain integral parameters during tropical convective (C), transition (T), and stratiform (S) types of rain are studied with the help of Joss-Waldvogel disdrometer (JWD), L-band, and very-high-frequency wind profilers at Gadanki $\left(13.5^{\circ} \mathrm{N}, 79.20^{\circ} \mathrm{E}\right)$. The classifications of three regimes are made with the help of an L-band wind profiler. For rain rate $R<10 \mathrm{~mm} \mathrm{~h}^{-1}$ larger drops are found in $\mathrm{S}$ type of rain relative to $\mathrm{C}$ and $\mathrm{T}$ rain, and for $R \geq 10 \mathrm{~mm} \mathrm{~h}^{-1}$ larger drops are found in convective rain. Empirical relations are developed for $D_{m}-R, D_{m}-Z, N_{0}^{*}-R, Z-R$, and $Z / D_{m}-R$ by fitting the power-law equations. Event to event, no systematic variation of the coefficients and exponents could be found for $Z-R$ and $Z / D_{m}-R$ relations during the three types of rain. Overall, the $\mathrm{C}$ and $\mathrm{S}$ events are found to be number controlled, and $\mathrm{T}$ events are size controlled. During $\mathrm{C}$ type of rain, bigger mean raindrops are found during the presence of strong updrafts. During $S$ type of rain, bigger mean raindrops are found to be associated with the higher mean thickness of the bright band and strong velocity gradient. For each of the developed empirical relations, the correlation coefficients are found in the order of $\mathrm{T}>\mathrm{C}>\mathrm{S}$ rain. During the three types of rain, correlations are found in the order of $Z / D_{\mathrm{m}}-R>Z-R>D_{m}-Z>D_{m}-R$. Significant improvement is observed in rain retrieval by using the $Z / D_{m}-R$ relation relative to the conventional $Z-R$ relation. By utilizing the $Z / D_{m}-R$ relations, the root-mean-square error was reduced by $19 \%-46 \%$.
\end{abstract}

\section{Introduction}

Raindrop size distribution (DSD) is one of the most fundamental rain parameters to study and characterize different precipitation systems. The shape of rain DSD represents the characteristics of rain and the physics of rain formation. The study of DSD is twofold. On one hand it contributes to a better understanding of microphysical and cloud processes in the generation of pre-

* Current affiliation: Indian Institute of Tropical Meteorology, Pune, India.

Corresponding author address: Dr. Sanjay Sharma, Department of Physics, Kohima Science College, Jotsoma, Kohima, Nagaland 797 002, India.

E-mail: sanjay_sharma11@hotmail.com cipitation particles (Gossard 1988; Tokay and Short 1996), and on the other hand it contributes to the remote measurement of precipitation by radars and satellites (Atlas et al. 1973; Doviak 1983; Jameson 1991; Atlas et al. 1999; Rajopadhyaya et al. 1999; Viltard et al. 2000). Most of the earlier works on DSDs were carried out with respect to rain intensity without taking into account the type of rain (Marshal and Palmer 1948; Joss and Gori 1978; Jones 1959; Sauvageot and Lacaux 1995). The DSDs associated with extreme rainfall rate, which are part of the convective systems, was studied by Willis and Tattelman (1989). Later on, DSDs are studied by classifying the precipitating systems mainly into convective and stratiform types and subsequently deduced the $Z-R$ relationships applicable to them (Tokay et al. 1999; Atlas et al. 2000; Ulbrich and Atlas 2002). Many studies have demonstrated that stratiform rain is 
TABLE 1. System parameters of L-band and VHF wind profilers and ESF information.

\begin{tabular}{lcc}
\hline \multicolumn{1}{c}{ Parameters } & L-band & VHF \\
\hline Frequency & $1357 \mathrm{MHz}$ & $53 \mathrm{MHz}$ \\
Antenna & $3.8 \mathrm{~m} \times 3.8 \mathrm{~m} \mathrm{Phased}$ array & $130 \times 130 \mathrm{~m}^{2}$ Yagi antenna \\
Peak power & $1 \mathrm{KW}$ & $2.5 \mathrm{MW}$ \\
Peak power aperture product & $1.2 \mathrm{~W} \mathrm{\textrm {m } ^ { 2 }}$ & $7 \times 10^{8} \mathrm{Wm}^{2}$ \\
Beam spread & $4^{\circ}$ & $3^{\circ}$ \\
Beam directions & Zenith & Zenith \\
Maximum duty & 0.05 & $1 \mu \mathrm{s}$ \\
Pulse width & $1 \mu \mathrm{s}$ & $250 \mu \mathrm{s}$ \\
Interpulse period & $80 \mu \mathrm{s}$ & 256 \\
No. of coherent integration & 64 & 256 \\
No. of FFT points & 128 & 1 \\
No. of incoherent integration & 64 & \\
\hline
\end{tabular}

characterized by larger raindrop diameters relative to convective type of rain for the same liquid water content (Tokay and Short 1996; Maki et al. 2001). During the Tropical Ocean and Global Atmosphere Coupled Ocean-Atmosphere Response Experiment (TOGA COARE), analysis of rain DSDs were carried out into two categories, namely, of broader and narrow DSD spectra. However, a correspondence between the broad and narrow DSD spectra and the stratiform and convective rainfall could not be found (Yuter and Houze 1997). Although studies have shown the differences in DSDs during stratiform and convective rainfall, there is still some uncertainty in the dependence of DSD on the type of precipitation. Later on many researchers reported the existence of a transition region between the convective and stratiform regimes (Williams et al. 1995; Maki et al. 2001; Steiner et al. 1995). Recently, Atlas et al. (1999), Rao et al. (2001), and Ulbrich and Atlas (2007) studied the DSDs during the three regimes and found the $Z-R$ relations for each regime. It is pointed out that there is a systematic variation of the $Z-R$ relations for these three types of rain (Atlas and Ulbrich 2006; Ulbrich and Atlas 2007). Reddy and Kozu (2003) proposed $Z-R$ relations for two different monsoon systems and reported that during the southwest monsoon (June-September) precipitation generally have bigger raindrops than during the northeast monsoon (October-December). Testud et al. (2001) have pointed out that the overall large variability of the rain integral parameters limit the parameterization of rain based on a single parameter. With the help of parameterization by intercept scaling parameter $\left(N_{0}^{*}\right)$ they showed that, even in the classified rain type, the rain-rate relations are much less dispersed than the conventional relations. Huggel et al. (1996) improved the rain retrieval during stratiform situation by using the dual parameters.

With this background, the present study is carried out at a tropical station, Gadanki, India. The basic objec- tives of the present work are (i) to study the characteristics of tropical DSDs in terms of bulk rain integral parameters during convective, transition, and stratiform rain and (ii) to develop the empirical relations for rainrate retrieval during these three regimes. The present paper is organized into five sections. In section 2 , the observational systems are described. The methodology for the classification of rain type is described in section 3 . The results are presented and discussed in section 4. In section 5, the conclusions of the present study are presented.

\section{Systems description}

The National Atmospheric Research Laboratory (NARL) at Gadanki $\left(13.5^{\circ} \mathrm{N}, 79.20^{\circ} \mathrm{E}\right)$, India, operates collocated L-band and very-high-frequency (VHF) wind profilers along with a Joss-Waldvogel disdrometer (JWD). Gadanki is situated in the tropical region of India and hence simultaneous observations by using these systems provide a good opportunity to study the tropical rain.

\section{a. L-band wind profiler}

In the present study, an L-band wind profiler is utilized to classify the type of precipitating systems and to estimate the rain integral parameters from its Doppler spectra. The basic features of the profiler and experimental specification file (ESF) information during precipitation studies are presented in Table 1 . The three moments of the Doppler spectra, namely the zeroth, first, and second, are calculated by the offline data processing. The three moments have physical meaning such as returned power (in arbitrary unit), Doppler shift (which subsequently gives the radial velocity of the target and its diameter), and variance or spectral width of the spectrum, respectively (Ralph et al. 1996). For the vertical incident beam of profiler, the fall velocity of raindrop is given by the following expression: 


$$
V=F_{d}(\lambda / 2),
$$

where $F_{d}$ is the Doppler shift of the precipitation echoes spectrum and $\lambda$ is the wavelength of the radar signal.

From the wind profiler, the mean drop diameter $\left(D_{\text {mean }}\right)$ is calculated by utilizing the equation as given by Atlas and Ulbrich (1977):

$$
V_{t}=\gamma\left(D_{\text {mean }}\right)^{0.67}
$$

where $\gamma=17.67 \mathrm{~m} \mathrm{~s}^{-1} \mathrm{~cm}^{-0.67}$ and $V_{t}$ is the terminal velocity of the raindrops.

During convective precipitation, the presence of updrafts-downdrafts has a direct effect on the fall velocity of the hydrometeor particles. In this regard, Cifelli and Rutledge (1994) studied the composite profiles of vertical air motion during convective, transition, and stratiform rain. In a convective region they reported the doublepeaked ascent profile with a peak located near 3 and $9 \mathrm{~km}$. The reported peaks of the composite profiles are of the order of 1-2 $\mathrm{m} \mathrm{s}^{-1}$. The composite profile in the transition region showed subsidence throughout the majority of the troposphere with dual peaks of comparable magnitudes at upper and lower levels. In the stratiform region, the composite profiles showed descending motion occurring below $\sim 8.5 \mathrm{~km}$, with a peak near the melting level, and double-peak ascent structure in the upper troposphere, with a magnitude of $\leq 0.5 \mathrm{~m} \mathrm{~s}^{-1}$. It is important to mention that during the convective situation the magnitude of the vertical air velocity is $<1.0 \mathrm{~m} \mathrm{~s}^{-1}$ at lower heights, and during transition and stratiform rain it is $<0.5 \mathrm{~m} \mathrm{~s}^{-1}$. Similar results are also reported by Balsley et al. (1988) and Kishore et al. (2005). These results are important in the context that for the present study the rain integral parameters are estimated with the help of the L-band wind profiler at $0.6 \mathrm{~km}$, thereby they are least affected by the clear-air vertical air motion. Therefore, for the present study it is assumed that from $0.6 \mathrm{~km}$ the raindrops are falling with terminal velocity and therefore that mean diameters from the profiler are estimated without applying the vertical air motion correction. Rajopadhyaya et al. (1998) reported that there is an almost linear dependence of the relative accuracy of median diameter with the magnitude of mean vertical velocity. It is notable that these errors are about $20 \%$ for a vertical velocity of $1.3 \mathrm{~m} \mathrm{~s}^{-1}$, and when the vertical velocity is $2.3 \mathrm{~m} \mathrm{~s}^{-1}$ the error is of about $50 \%$. Kirankumar et al. (2008) pointed out that for an uncorrected velocity of $0.5 \mathrm{~m} \mathrm{~s}^{-1}$ the error in median diameter is around $10 \%$. Sharma et al. (2008) have reported that during convective rain, when the vertical clear-air velocity correction is applied, the root-meansquare error (rmse) of $D_{m}$ estimation by the L-band profiler at $1.8 \mathrm{~km}$ is reduced by $\sim 11 \%$. Similarly during the stratiform rain it is reduced by $\sim 7 \%$.

Further, for the meteorological applications, the wind profilers suffer from certain limitations. During clear-air measurements the clear-air wind profiler receiver has a linear response. However, during rain, when the backscattered signal is very strong, the profiler receiver has a nonlinear response; that is, an increase in the incident power produces only a small increase in the measured signal power (Ralph et al. 1995). At some point the receiver even becomes completely saturated and further increase in incident power leads to no measurable increase in signal power. Therefore, it becomes very difficult to calibrate the wind profilers, which implies that radar reflectivity factor $(Z)$ cannot be determined directly. For the present study the L-band wind profiler is calibrated with the help of JWD by using the nonparametric method as described by Konwar et al. (2008). For the L-band wind profiler the measured parameters are available from $300 \mathrm{~m}$ onward, but because of the presence of ground clutter data from $600 \mathrm{~m}$ onward only are considered.

\section{b. VHF wind profiler}

The VHF profiler $(53 \mathrm{MHz})$ is sensitive to clear-air echoes because of the refractive index gradient in clear air. The main features of VHF profiler and ESF information during precipitation studies are also presented in Table 1 . The estimation of clear-air vertical velocity during rain is carried out with the help of the zenith beam of the profiler. For the rain events under study, separate peaks for precipitation and clear-air echoes are observed during heavy rain. The clear-air spectral peaks are analyzed after separating them from the rain echoes. Further, the clear-air vertical velocity is calculated by using the Eq. (1). The positive and negative Doppler shifts signify the downdrafts and updrafts, respectively.

\section{c. Joss-Waldvogel disdrometer}

The JWD is a standard tool for precipitation measurements such as DSD, rainfall intensity $R$, rain accumulation, and radar reflectivity factor $Z$ (Waldvogel 1974). The range of drop diameters that can be measured spans from 0.3 to $5.0 \mathrm{~mm}$ with an accuracy of $5 \%$. The limitation of JWD is that it is sensitive to background noise. Laboratory measurements have revealed that a noise level of $50 \mathrm{~dB}$ or less had little effect on signals corresponding to drop diameters of $0.3-0.4 \mathrm{~mm}$, whereas a noise level of $55 \mathrm{~dB}$ reduced the detected number of such sized drops significantly. When noise level reached $70 \mathrm{~dB}$, detection of drops of $0.3-0.8$ mm-diameter is almost completely suppressed (Tokay et al. 2003). During high rain, lower channels, that is, first and second, show the zero number of drops that are 
considered because of the dead time error. During the Tropical Rainfall Measuring Mission (TRMM) ground validation field campaign in central Florida, it is observed that JWD underestimates the number of small drops relative to the $2 \mathrm{D}$ video disdrometer (Williams et al. 2000). It is also noticed that a continuous increase in the number of drops toward smaller size was only evident in video disdrometer at rain rate above $20 \mathrm{~mm} \mathrm{~h}^{-1}$ (Tokay et al. 2001). Despite these limitations, JWD is still considered a standard tool for the measurements of the bulk descriptors of rainfall. The bulk descriptors of rainfall such as rainfall intensity $(R)$, radar reflectivity factor $(Z)$, mass weighted mean diameter $\left(D_{m}\right)$, and scaling parameter for concentration or normalized intercept parameter $\left(N_{0}^{*}\right)$ (Testud et al. 2001) are calculated by the following expressions:

$$
\begin{aligned}
R\left(\mathrm{~mm} \mathrm{~h}^{-1}\right) & =(\pi / 6)\left(3.6 / 10^{3}\right)(1 / A T) \sum_{i=1}^{20}\left(n_{i} D_{i}^{3}\right) \\
Z\left(\mathrm{~mm}^{6} \mathrm{~m}^{-3}\right) & =(1 / A T) \sum_{i=1}^{20}\left[n_{i} / v\left(D_{i}\right)\right] D_{i}^{6} \\
D_{m}(\mathrm{~mm}) & =\sum_{i=1}^{20}\left[n_{i} / v\left(D_{i}\right)\right] D_{i}^{4} / \sum_{i=1}^{20}\left[n_{i} / v\left(D_{i}\right)\right] D_{i}^{3} \\
N_{0}^{*} & =4^{4} \times \mathrm{LWC} / \pi \rho_{w} D_{m}^{4}
\end{aligned}
$$

where $A$ is a collecting area of JWD, $T$ is the integration time, and $n_{i}$ and $D_{i}$ are number of drops and drop diameter $(\mathrm{mm})$ of the $i$ th channel of JWD, respectively. The $v\left(D_{i}\right)$ is the terminal velocity $\left(\mathrm{m} \mathrm{s}^{-1}\right)$ of the raindrops in the $i$ th channel and is estimated by $V\left(D_{i}\right)=$ $9.65-10.3 \exp \left(-6 . D_{i}\right)$ (Gunn and Kinzer 1949). LWC is the liquid water content, that is, the third moment of the DSD spectra, and $\rho_{w}$ is the density of the water.

For the validation of JWD, the rain intensity measured by JWD is compared with optical rain gage (ORG) measurements. From the available simultaneous dataset of JWD and ORG, the comparison is carried out for seven rain events. For the present study, the rain intensity $\geq 0.5 \mathrm{~mm} \mathrm{~h}^{-1}$ are considered to be rainy minutes. The scatterplot for overall JWD- and ORG-measured rain intensity is shown in Fig. 1. A linear fit is carried out to the scatterplot. The error statistics is provided in the figure panel. The bias is estimated with respect to JWD observations. It is observed that the gradient of the linear fit is 1.30 . The positive bias indicates that the JWD-measured rain rate is overestimated relative to ORG measurements. The correlation coefficient is reasonably good between these two measurements. Further,

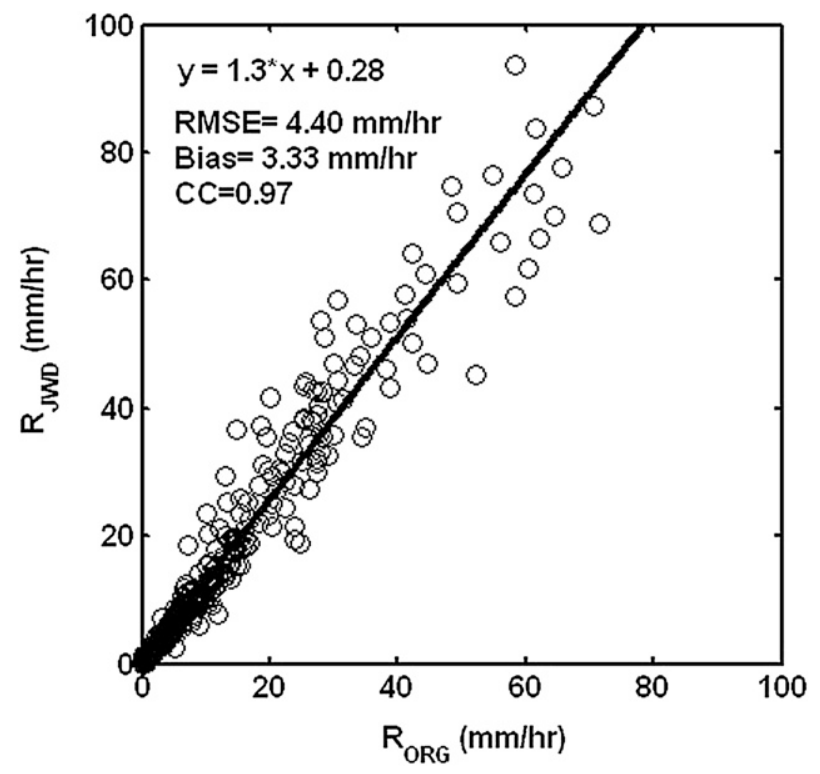

FIG. 1. Scatterplot for JWD- vs ORG-measured rainfall intensity.

for individual rain events, the linear fit parameters and error statistics for the simultaneous measurements of rain intensity from these two measuring systems are provided in Table 2. The total rain accumulation of rain with JWD and ORG is compared with varying statistical errors. It is noticed that the JWD is consistently overestimating the rain intensity. At Gadanki, similar results are also reported by Rao et al. (2001).

\section{d. Intercomparison of the L-band profiler and JWD estimated rain integral parameters}

The intercomparison of the L-band profiler and JWD-measured mean diameter $\left(D_{\text {mean }}\right)$ and reflectivity $(\mathrm{dBZ})$ are also carried out for all the selected events. The $D_{\text {mean }}$ from L-band wind profiler and JWD are estimated by using the Eqs. (2) and (5), respectively. The L-band profiler measurements are at $0.6 \mathrm{~km}$. To make the near-simultaneous data points of these two systems, a time lag is incorporated because of the falling raindrops from a height of $0.60 \mathrm{~km}$. The time lag is calculated with the help of a fall velocity parameter $\left(V_{D}\right)$ at $0.60 \mathrm{~km}$. To match the different integration time of the two systems, averaging of the DSD spectra at ground is carried out. The integration time for each vertical beam of profiler is nearly $3 \mathrm{~min}$. Therefore, DSDs from JWD are averaged for $3 \mathrm{~min}$. Hence, the mean $D_{m}$ measurements from both the sensors are the average value of $3 \mathrm{~min}$. The scatterplots for overall JWD- and profiler-measured $D_{\text {mean }}$ and $\mathrm{dB} Z$ are shown in Figs. 2a and 2b, respectively. A linear fit is carried out to these scatterplots. The error statistics is provided in the respective figure panels. Bias is estimated with 
TABLE 2. Comparison of the JWD retrieved rain rate with ORG measurements for different rain events.

\begin{tabular}{|c|c|c|c|c|c|c|}
\hline \multirow[b]{2}{*}{ Events } & \multicolumn{2}{|c|}{$\begin{array}{l}\text { Parameters for best-fit } \\
\text { linear equation }\end{array}$} & \multirow[b]{2}{*}{ Rmse $\left(\mathrm{mm} \mathrm{h}^{-1}\right)$} & \multirow{2}{*}{$\begin{array}{l}\text { Correlation } \\
\text { coef }\end{array}$} & \multicolumn{2}{|c|}{ Rain accumulation $(\mathrm{mm})$} \\
\hline & Gradient & Intercept & & & JWD & ORG \\
\hline 17 May 1999 & 1.10 & 1.90 & 5.04 & 0.98 & 28.90 & 23.32 \\
\hline 17 Jul 1999 & 1.10 & 0.29 & 1.42 & 0.96 & 2.12 & 1.73 \\
\hline 26 Aug 1999 & 1.50 & -0.34 & 5.45 & 0.98 & 24.91 & 18.31 \\
\hline 21 Jun 2000 & 1.30 & 0.04 & 0.39 & 0.95 & 3.47 & 2.83 \\
\hline 22 Jun 2000 & 1.30 & -0.91 & 2.95 & 0.98 & 49.08 & 40.16 \\
\hline 28 Jul 2000 & 1.50 & 1.00 & 5.43 & 0.93 & 8.49 & 5.38 \\
\hline $29 \mathrm{Jul} 2000$ & 1.30 & -0.39 & 1.36 & 0.99 & 16.39 & 13.22 \\
\hline
\end{tabular}

respect to JWD observations. As evident from the negative bias in both the panels, although overall JWD measurements are underestimated relative to profiler measurements, reasonably good agreement is found between these two measurements. The observed negative biasing may be attributed to the various factors such as (i) no correction of clear-air vertical velocity to the hydrometeor fall velocities, as the clear-air vertical air motion at the lower heights is not available; (ii) the effect of evaporation while raindrops fall from $0.6 \mathrm{~km}$ to the ground; (iii) different approach of measurements, that is, while profiler measurements are reflectivity weighted $\left(\sim D^{6}\right)$ and JWD measurements are mass weighted $\left(\sim D^{3}\right)$; and (iv) different sampling volumes of the two systems.

\section{Classification of precipitating systems}

One of the important aspects of studying DSD dependence on rain types is the establishment of an objective rain type classification methodology. Many schemes have been developed for separating the precipitating systems into different regimes by using various observational systems, that is, disdrometer (Atlas et al. 1999; Rao et al. 2001; Testud et al. 2001), radar echo structures (Biggerstaff and Listema 2000), satellite observations (Hong et al. 1999), and wind profilers (Williams et al. 1995; Rao et al. 1999). By using the wind profiler measurements the precipitation systems are broadly classified into three categories, that is, stratiform, transition (mixed stratiform/convective), and convection on the basis of an algorithm as proposed by Williams et al. (1995). Their algorithm is based on the following criteria that (i) either a melting layer signature is present or absent, (ii) either enhanced turbulence is present or absent above the melting layer signature, or (iii) either hydrometeors are present or absent above the melting level. On the basis of these criteria, the algorithm first looks for the stratiform regime then the transition and convective regimes. To classify the pre- cipitating systems, the three moments-that is, backscattered power in terms of reflectivity, mean Doppler shift, and spectral width of the backscattered signalare utilized (Ralph 1995; Ralph et al. 1995). In the original algorithm the cloud systems are organized into four systems, but in the present study we have categorized clouds into three types, namely, stratiform, transition, and convective clouds. The shallow and deep convective clouds are included in the same convective type. The stratiform class is characterized by the presence of the melting layer signature as identified by the change in the hydrometeor fall speed, that is, Doppler velocity gradient (DVG) and maximum spectral width (MSW). For the present study, the DVG and MSW thresholds used to determine stratiform regimes are as follows:

DVG $>2.0 \mathrm{~m} \mathrm{~s}^{-1} \mathrm{~km}^{-1}$ for $3.5 \mathrm{~km}<$ height $<5.0 \mathrm{~km}$,

MSW $<2.5 \mathrm{~m} \mathrm{~s}^{-1}$ for $7.0 \mathrm{~km}<$ height.

The mixed stratiform-convective (transition) class is separated from the stratiform class by the increased turbulent motions above the melting layer signature, with the criteria that

$$
\text { MSW } \geq 2.5 \mathrm{~m} \mathrm{~s}^{-1} \text { for } 7.0 \mathrm{~km}<\text { height. }
$$

If the precipitation clouds do not have the melting layer signature, then the precipitation clouds are classified as one of the two different convective cloud types, that is, deep convective and shallow convective clouds. The deep convective class has reflectivity echoes up to higher heights above the melting level, while the shallow convective class does not have reflectivity signatures above the melting levels. The shallow convective clouds are discriminated with deep convective by the following criteria:

$$
V_{d} \leq-0.5 \mathrm{~m} \mathrm{~s}^{-1} \text { for } 5.0 \mathrm{~km}<\text { height. }
$$

The typical height-time-intensity (HTI) plots of radar reflectivity factor, spectral width of the Doppler 

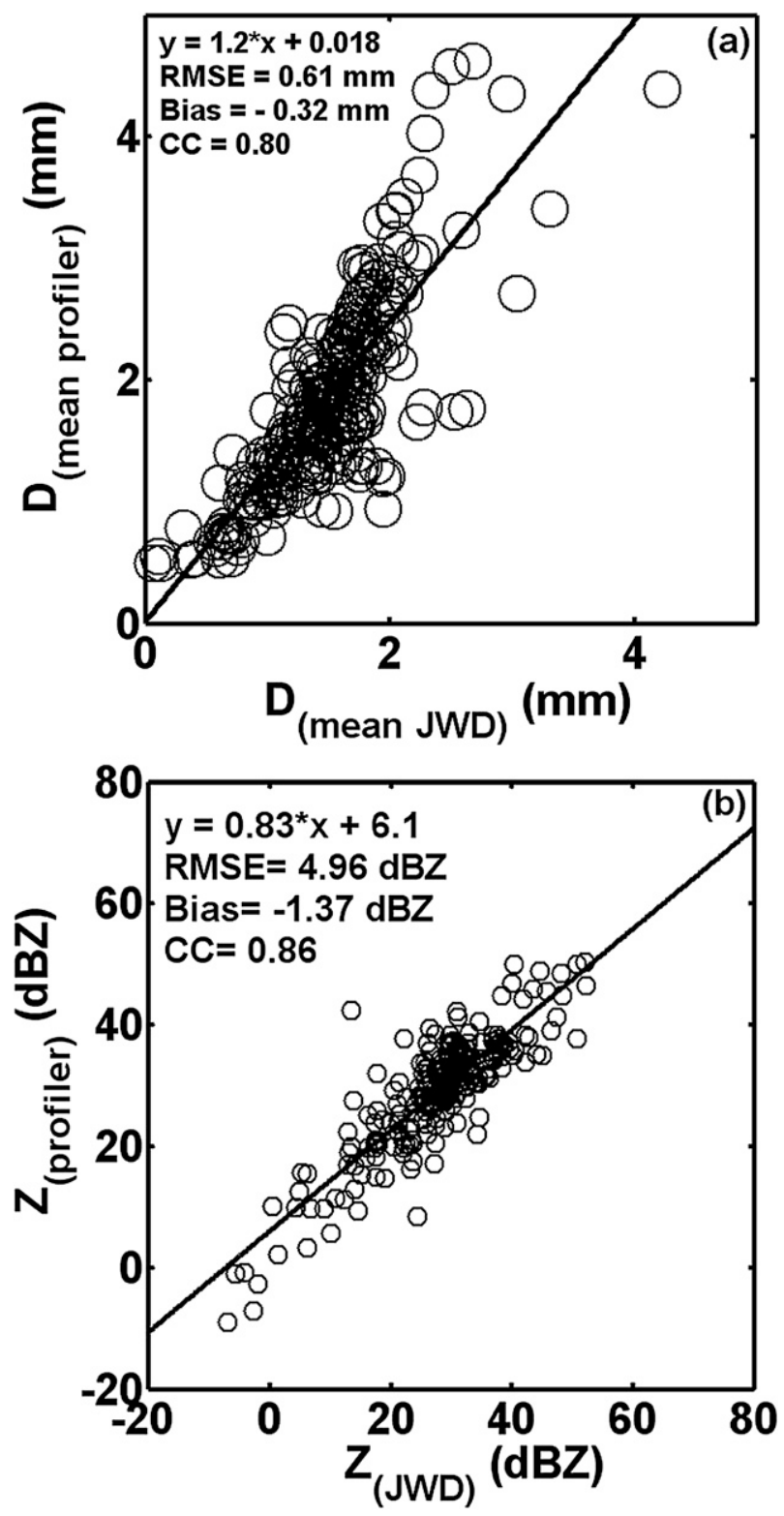

FIG. 2. Scatterplots for JWD- vs L-band-profiler-measured (a) mean raindrop diameter and (b) radar reflectivity factor.

spectra, and the Doppler velocity gradient of mean raindrops for the vertical beam are shown in Figs. 3a, 3b, and $3 \mathrm{c}$, respectively. The temporal variations of the observed parameters are provided in Indian standard time (IST), which is $5 \mathrm{~h} 30 \mathrm{~min}$ ahead of UTC. This event, on 22-23 June 2000, consists of all the three types of rain. The convective system is identified from 2143 to $2238 \mathrm{~h}$ by virtue of (i) high values of reflectivity of the order of $\sim 50 \mathrm{dBZ}$ up to higher heights, that is, $8 \mathrm{~km}$, indicating the presence of deep convective system; (ii) high values of spectral width of the order of $1.5-3.0 \mathrm{~m} \mathrm{~s}^{-1}$ up to $8.0 \mathrm{~km}$; and (iii) absence of bright band. After the convective regime, the transition period is identified from 2239 to $0127 \mathrm{~h}$ by virtue of the absence of a high reflectivity column and the presence of turbulence as indicated by the high spectral width of the order of $1.0-1.5 \mathrm{~m} \mathrm{~s}^{-1}$ above the weak bright band. The weak bright band is indicated by the low value of the Doppler velocity gradient of the order of $3-4 \mathrm{~m} \mathrm{~s}^{-1} \mathrm{~km}^{-1}$ at around $4-5 \mathrm{~km}$. Finally, the stratiform regime is identified from 0128 to $0650 \mathrm{~h}$ by virtue of the presence of strong bright band as indicated by the high values of Doppler velocity gradient of the order of $7-9 \mathrm{~m} \mathrm{~s}^{-1} \mathrm{~km}^{-1}$ at around $4.0-\mathrm{km}$ height and the absence of turbulence above the melting level. The absence of turbulence above the bright band is attributed to the low values of the spectral width, that is, $<1.5 \mathrm{~m} \mathrm{~s}^{-1}$.

By using the above-mentioned methodology, seven rain events are classified into convective, transition, and stratiform rain. To study the DSD characteristics during convective, transition, and stratiform rain, simultaneous L-band wind profiler and JWD observations are considered. Out of these seven rain events, the rain events on 17-18 May 1999, 26 August 1999, 22-23 June 2000, and 17 July 2000 consist of all the three regimes. On 18 August 1999 the rain event consists of convective and transition region and on 28 July 2000 and 21 June 2000 the rain events consist of only convective and stratiform rain, respectively. These observations were carried out at NARL during the convection-precipitation campaign from the year 1998 to 2000. The present classification methodology is also compared with the classification methodology proposed by Testud et al. (2001). However, in the rain classification scheme of Testud et al. (2001), the authors did not categorize the transition type of rain. Their classification scheme is based on the temporal variability of rainfall intensity $R$. They considered an along track series $\left(R_{i}\right)$ of the rainfall rate where the subscript stands for each individual spectrum. If $R_{k}$ and the 10 adjacent values, that is, from $R_{k-5}$ to $R_{k+5}$, are all less than $10 \mathrm{~mm} \mathrm{~h}^{-1}$, then spectrum $k$ is considered to be stratiform rain; otherwise, spectrum $k$ is classified as convective. This investigation is made only to demonstrate the importance of transition region that is considered in this study. For this purpose the case studies are carried out on 17-18 May 1999, 26 August 1999, 17 July 1999, 21 June 2000, 22-23 June 2000, and 18 August 1999 to examine which portion of the DSD spectra is classified in the same category by both the methods. The fractions for convective and stratiform rain as accounted for by these two methods for these days are provided in Table 3. It is observed that the Testud et al. (2001) scheme accounted for the greater fraction of the convective and stratiform regimes for the obvious reason of no consideration of transition rain. 

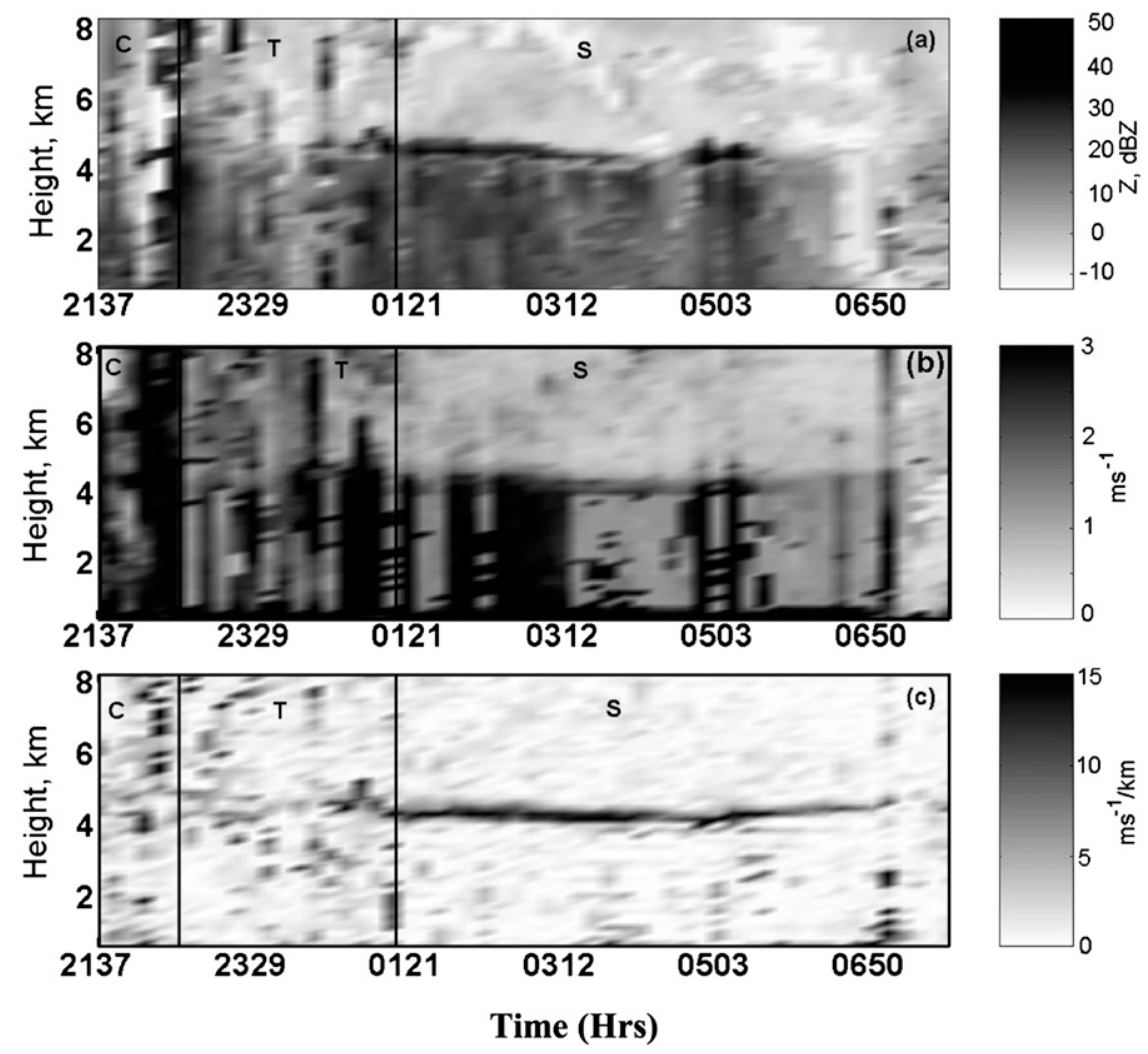

FIG. 3. The HTI plots for (a) radar reflectivity factor, $Z$ (dBZ); (b) spectral width $\left(\mathrm{m} \mathrm{s}^{-1}\right)$; and (c) Doppler velocity gradient $\left(\mathrm{m} \mathrm{s}^{-1} \mathrm{~km}^{-1}\right)$ on 22-23 Jun 2000.

Testud et al. (2001) schemes accounted for approximately $90 \%-100 \%$ more for the convective rain and approximately $30 \%-40 \%$ more for stratiform rain relative to Williams' schemes. It is also noticed that the transition region is accounted for significantly by the Williams' scheme. The occurrence of the transition region from event to event is found to vary from $7 \%$ to $70 \%$ of the total time of the rain event.

\section{Results}

To study the characteristics of rain integral parameters during convective, transition, and stratiform rain, seven rain events are selected and analyzed with the help of simultaneous observations from L-band/VHF wind profilers and JWD. The selected rain events consist of total 411 DSD spectra during convective, 265 spectra during transition, and 700 spectra during stratiform rain. The overall analysis of the DSDs at Gadanki is presented in three parts: (i) study of the characteristics of rain integral parameters with respect to rain rate during convective, transition, and stratiform rain; (ii) study of the variability of the rain integral parameters with respect to different microphysical process in convective and stratiform rain; and (iii) development of the dual parameterization scheme for rain-rate retrieval. The analysis details are presented in the following sections.

\section{a. Characteristics of rain integral parameters during convective, transition, and stratiform rain at Gadanki}

From the prepared dataset of DSDs, the occurrence of $D_{\mathrm{m}}$ is studied in terms of frequency distribution during

TABLE 3. Comparison of two different methodologies for rain type classification (\%).

\begin{tabular}{lcccccc}
\hline \hline \multirow{2}{*}{ Dates } & \multicolumn{2}{c}{ Williams et al. (1995) } & & \multicolumn{2}{c}{ Testud et al. (2001) } \\
\cline { 2 - 3 } \cline { 5 - 6 } \cline { 5 - 6 } & Convective & Stratiform & & Convective & Stratiform \\
\hline 17-18 May 1999 & 8 & 71 & & 13 & 87 \\
26 Aug 1999 & 9 & 84 & & 18 & 82 \\
17 Jul 1999 & 6 & 52 & & 12 & 88 \\
21 Jun 2000 & - & - & & - & 100 \\
22-23 Jun 2000 & 10 & 59 & & 22 & 78 \\
18 Aug 1999 & 30 & - & & 67 & 33 \\
\hline
\end{tabular}



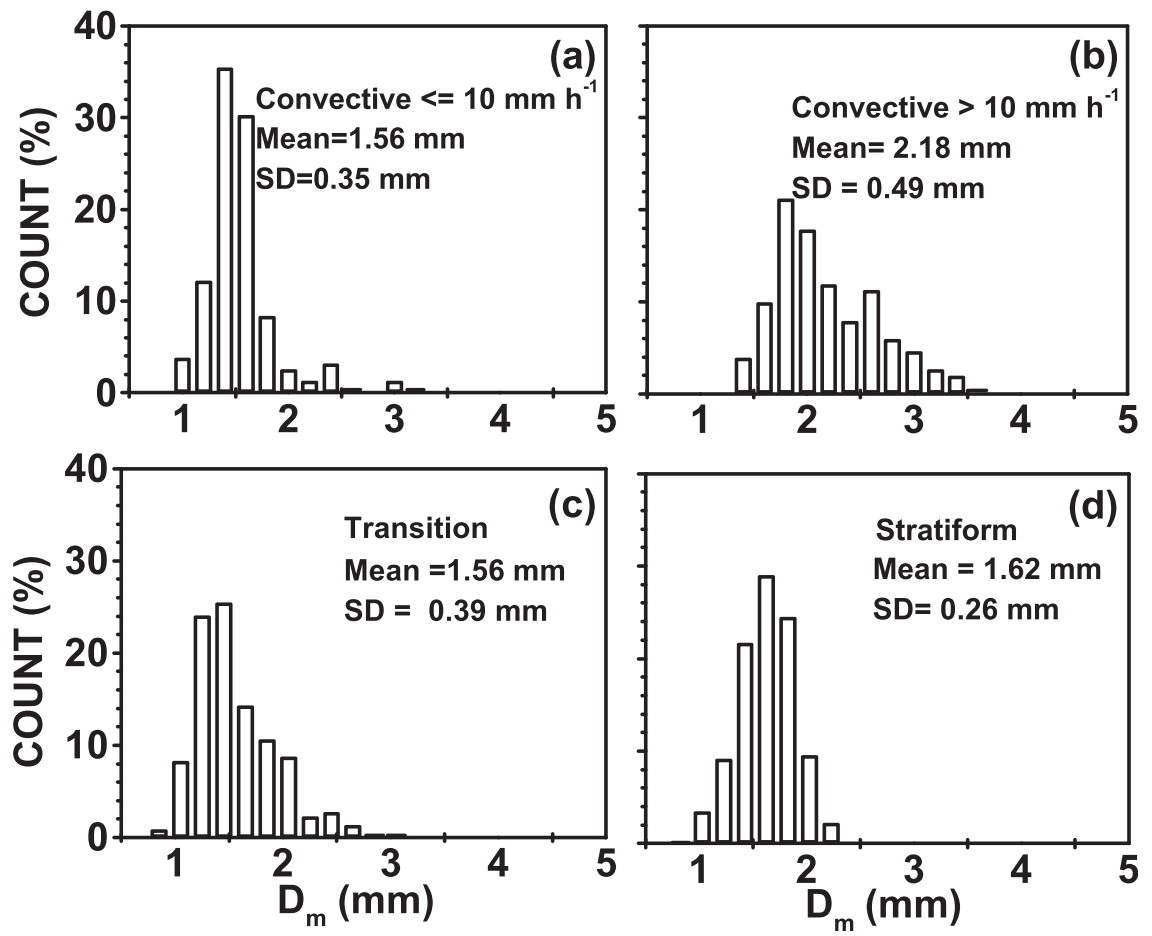

FIG. 4. Frequency distribution of $D_{m}(\%)$ for the classified data obtained from all the selected rain events during (a) convective rain I, (b) convective rain II, (c) transition rain, and (d) stratiform rain.

three types of rain. The frequency distribution of $D_{m}$ during convective rain is divided into two groups: convective I $\left(R \leq 10 \mathrm{~mm} \mathrm{~h}^{-1}\right)$ and convective II $\left(R>10 \mathrm{~mm} \mathrm{~h}^{-1}\right)$. The frequency distributions of the occurrence of $D_{m}$ during convective I, convective II, transition, and stratiform rain are shown in Figs. 4a, 4b, 4c, and 4d, respectively. The mean values of $D_{m}$ during convective rain for these two ranges are 1.56 and $2.18 \mathrm{~mm}$, with a standard deviation (std dev) of 0.35 and $0.49 \mathrm{~mm}$, respectively. During the transition and stratiform rain, mean values of $D_{m}$ are found to be 1.56 and $1.62 \mathrm{~mm}$ with a standard deviation of 0.39 and $0.26 \mathrm{~mm}$, respectively. During convective II $\left(R>10 \mathrm{~mm} \mathrm{~h}^{-1}\right)$, larger drops are observed quite significantly compared to convective I, transition, and stratiform rain. It is interesting to note that, for $R<10 \mathrm{~mm} \mathrm{~h}^{-1}, D_{m}$ is larger for stratiform rain compared to convective I events. To further study the variability of $D_{m}$ with respect to $R$, the scatterplots of $D_{m}$ versus $R$ during convective, transition, and stratiform rain are shown in Figs. 5a, 5b, and $5 \mathrm{c}$, respectively. The power-law equations are fitted to these scatterplots. The coefficient and exponent values of the fitted power-law equations are provided in the respective figure panels. For $D_{m}-R$ plots, the coefficients and exponents are in the order of $\mathrm{S}>\mathrm{C}>\mathrm{T}$ and $\mathrm{T}>\mathrm{C}>\mathrm{S}$, respectively. This nature of variation of coefficient and exponent indicates that, for a given rain rate, overall mean raindrops are bigger during stratiform regimes but the sensitivity of $D_{m}$ with respect to $R$ is minimum in stratiform rain. This result is consistent with the fact that, at lower rain intensity, the stratiform regime has larger mean drops compared to convective and transition regimes, but, on the other hand, at higher rain intensity range the $D_{m}$ is larger in convective rain relative to other two types of rain, as noticed in Figs. 4a-d also. To study the variability of $D_{m}$ with respect to $Z$, the scatterplots for $D_{m}$ versus $Z$ during convective, transition, and stratiform rain are shown in Figs. 6a, 6b, and $6 c$, respectively. The power-law equations are fitted to these scatterplots. The values of the coefficient and exponent of the derived power-law equations for each type of rain are provided in the respective figure panels. The coefficients and exponents are in the order of $\mathrm{S}>\mathrm{C}>\mathrm{T}$ and $\mathrm{T}>\mathrm{C}>\mathrm{S}$, respectively, thereby indicating that overall mean raindrops are bigger during the $\mathrm{S}$ regimes, but by virtue of the lowest value of the exponent the sensitivity of the $D_{\mathrm{m}}$ with respect to $Z$ is minimum. These results are similar to $D_{\mathrm{m}}-R$ relations. The characteristic of $D_{m}$ at Gadanki is very similar in nature to the results reported by Testud et al. (2001). They studied the frequency distribution of the occurrence of $D_{m}$ with respect to types of rain as well as rain intensity over 

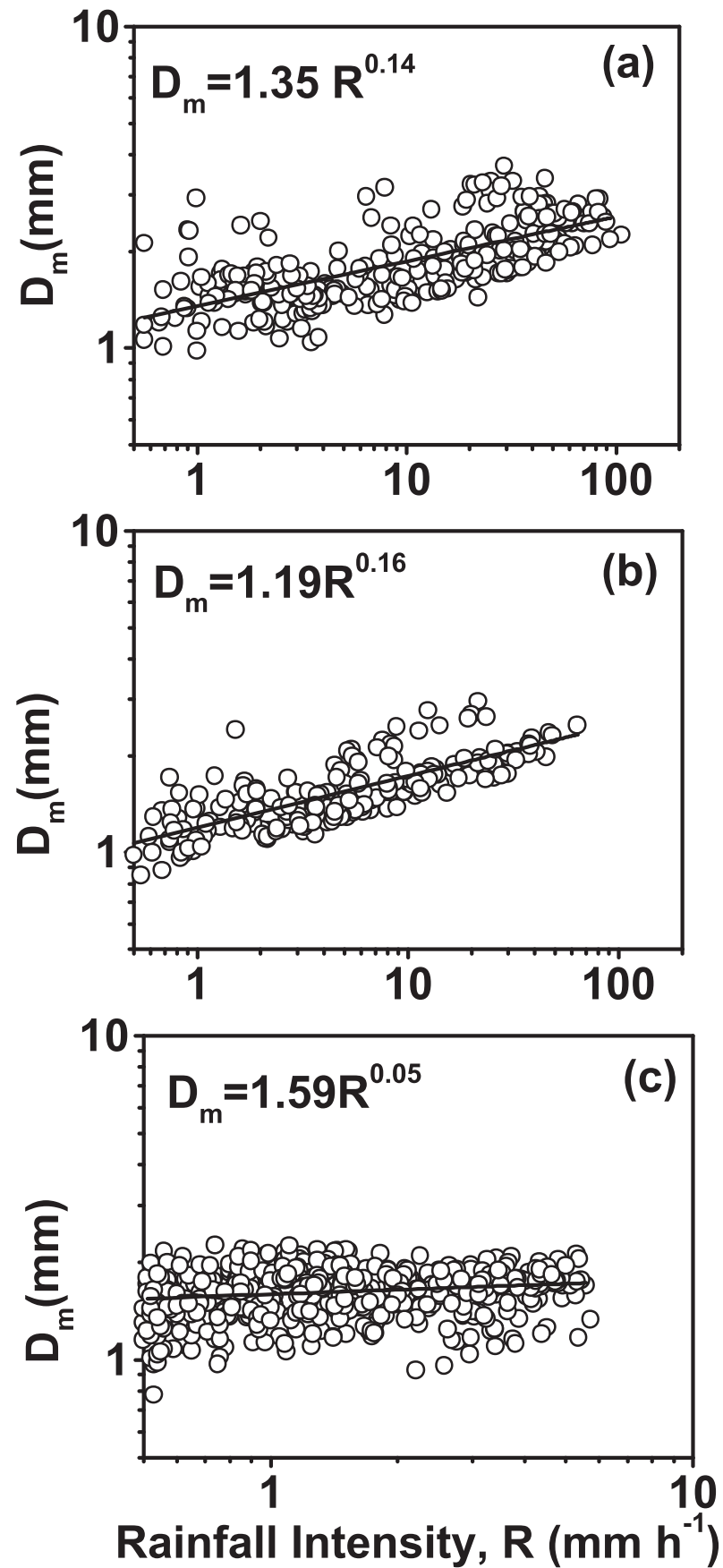

FIG. 5. Scatterplots for $D_{m}$ vs $R$ for all the selected rain events during (a) convective, (b) transition, and (c) stratiform rain.

the west Pacific Ocean under the TOGA COARE program. In the range of rain intensity $0<R \leq 10 \mathrm{~mm} \mathrm{~h}^{-1}$, they reported the mean values of $D_{m}$ for stratiform and convective rain to be 1.30 and $1.19 \mathrm{~mm}$, respectively. For convective rain, in the rain intensity range of $10<$ $R \leq 30 \mathrm{~mm} \mathrm{~h}^{-1}$ the mean value of $D_{m}$ is $1.40 \mathrm{~mm}$, and for the $30<R \leq 100 \mathrm{~mm} \mathrm{~h}^{-1}$ it is found to be $1.78 \mathrm{~mm}$.
It is also important to point out that the higher value of $D_{m}$ for the convective rain $\left(R \geq 10 \mathrm{~mm} \mathrm{~h}^{-1}\right)$ at Gadanki relative to the TOGA COARE observation may be due to the classification of the rain into three types of rain at Gadanki, whereas for the latter work, rain events were classified only as convective and stratiform. At lower rain intensity, similar results were also reported by Tokay and Short (1996) and Atlas et al. (2000). For the stratiform rain, Maki et al. (2001) also reported larger drop spectrum and reflectivity trough for the same liquid water content, relative to the convective center. It is pointed out by Stewart et al. (1984) that the aggregation of hydrometeors at the height of the bright band produces large raindrops in the stratiform region.

The scatterplots for $Z$ versus $R$ during convective, transition, and stratiform rain are shown in Fig. $7 \mathrm{a}, 7 \mathrm{~b}$, and $7 \mathrm{c}$, respectively. The power-law equations are fitted to these scatterplots and the values of coefficients and exponent for each type of rain are provided in the respective figure panels. It is observed that coefficients for $Z-R$ relations are predominantly larger during convective and stratiform rain compared to transition rain. For the overall $Z-R$ relations the coefficients and exponents are in the order of $\mathrm{C}>\mathrm{S}>\mathrm{T}$ and $\mathrm{T}>\mathrm{C}>\mathrm{S}$. The similar nature of the result is also pointed out by Atlas and Ulbrich (2006). The coefficient and exponent of the $Z-R$ relation for each type of rain for the selected rain events are estimated separately and are provided in Table 4. It is observed that, eventwise, there is no systematic variation of coefficients and exponents among these three different regimes. It is also noticed that there are wide variations in the coefficient values during the convective rain compared to stratiform rain. The large difference in the coefficients between 18 August (1865) and 22 June (129) may be attributed to the different magnitudes of the prevailing updrafts-downdraft. The general observed feature of stratiform rain, that is, large coefficients and small exponents, may be attributed to the melting of large snow flakes below a strong bright band (Atlas and Ulbrich 2006). In their study of microphysical interpretation of the $Z-R$ relation, Steiner et al. (2004) pointed out that the variability of the raindrop size distribution is bounded by either size or number controlled conditions, with conditions of a coordinated mixed control embedded in between those extremes. On the basis of raindrop spectra observations from JWD, Smith and Krajewski (1993) found the limiting values of the exponent $b$ for number controlled and size controlled to be $1 \leq b<1.79$. From our observations at Gadanki, on average it is found that the microphysical process are different for convective, transition, and stratiform rain, but by virtue of low values of the exponent $b$ (in $Z=A R^{b}$ ), the convective 

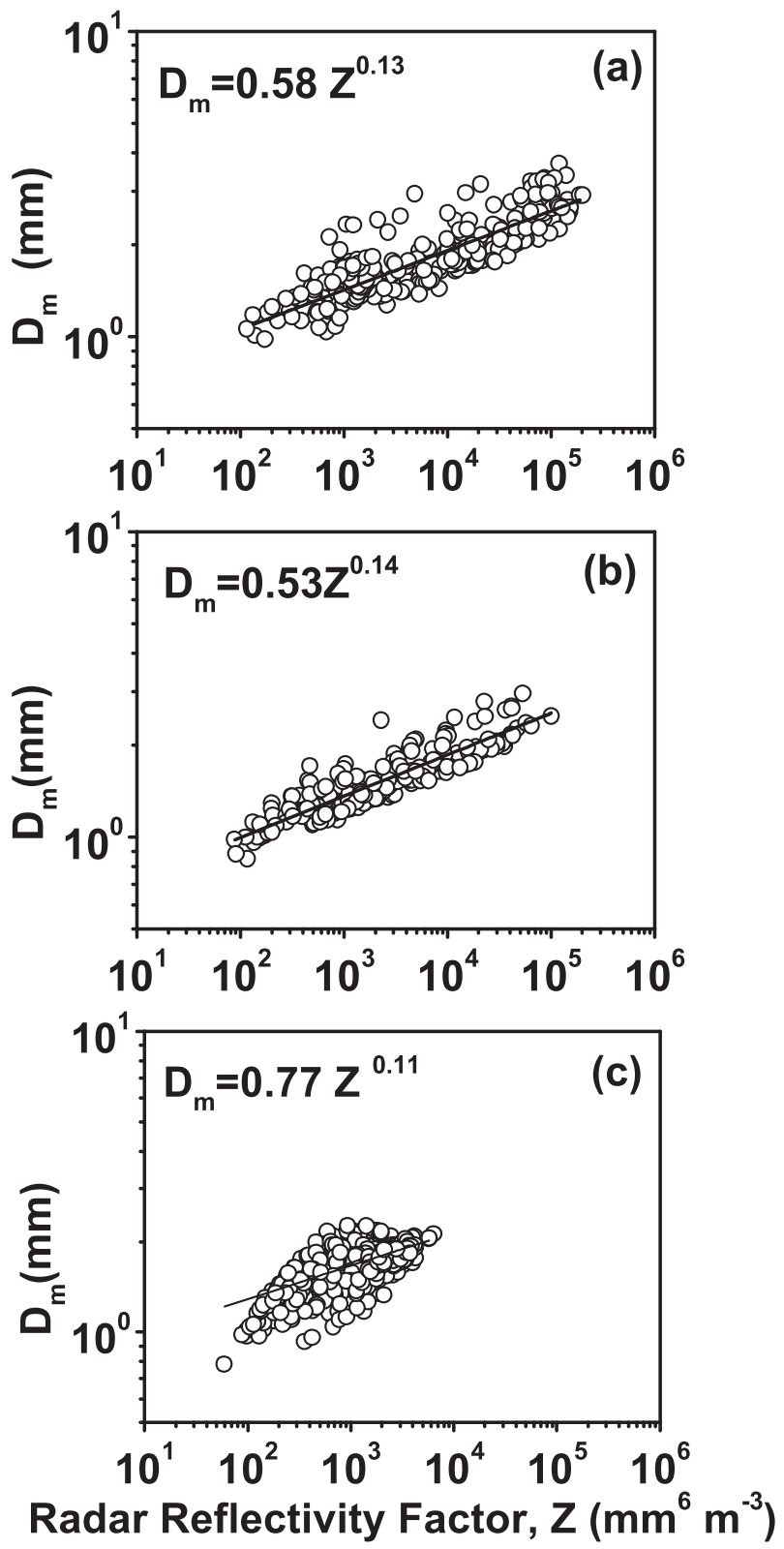

FIG. 6. As in Fig. 5, but for $D_{m}$ vs $Z$.

and stratiform events are primarily number controlled, and by virtue of a high value of $b$, transition events are either size or mixed controlled phenomena. Furthermore, the variability of the coefficient and exponents of $Z-R$ relations during these three types of rain at Gadanki are compared with the results reported by various researchers over different regions of the globe. The numerous $Z-R$ relations, as developed by various researchers, for individual as well as for combined rain events are provided in Table 5 . The proposed $Z-R$ relations for individual rain events by Ulbrich and Atlas (2007) and Atlas et al. (1999) are at Arecibo, Puerto

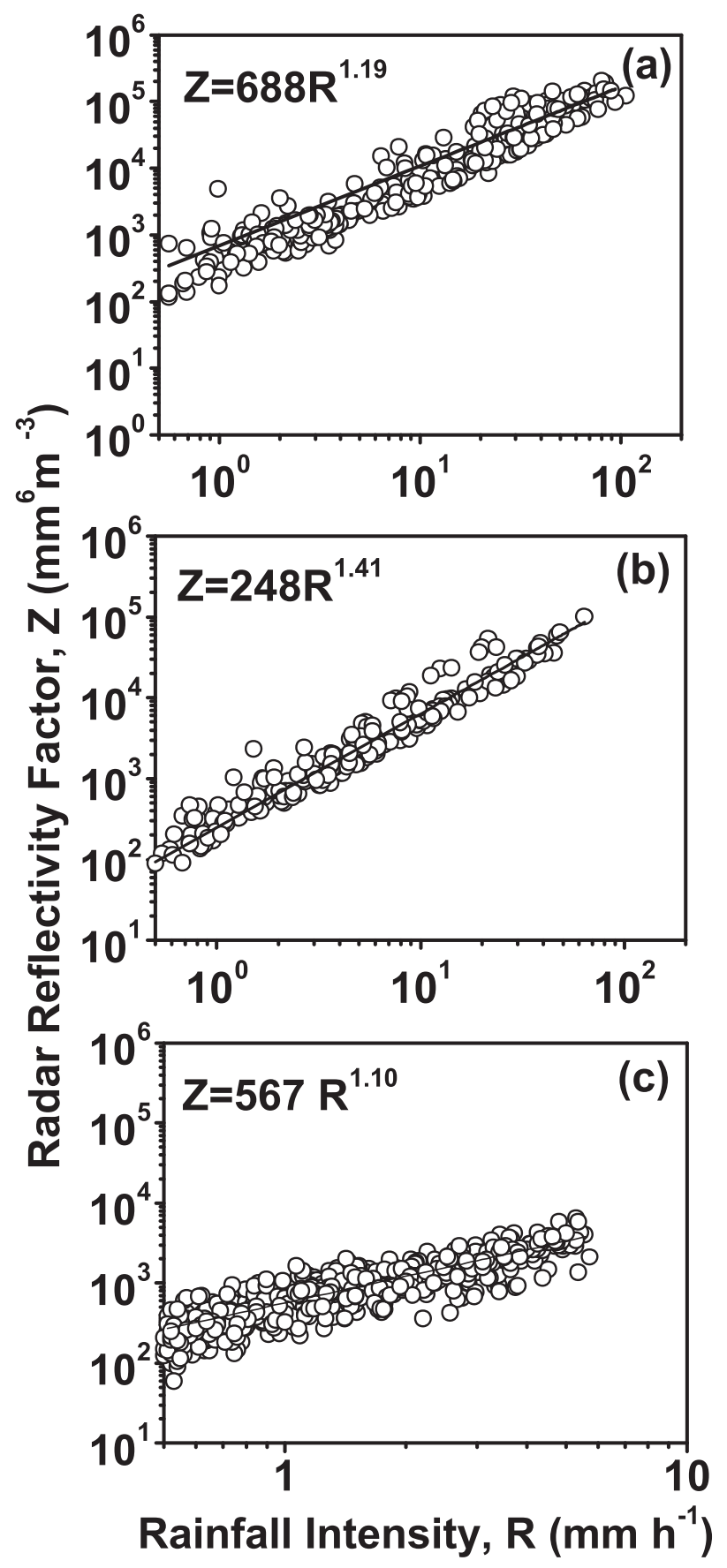

FIG. 7. As in Fig. 5, but for $Z$ vs $R$.

Rico, and Kapingamarangi Atoll, respectively. The proposed $Z-R$ relations for individual and combined rain events by Rao et al. (2001) are at Gadanki, India. At Gadanki, for the combined rain events, the DSD observations are during September-December 1997 and May-August 1999. Maki et al. (2001) derived the $Z-R$ relations from the 15 continental squall lines events. Their observations are during 26 December 1997 
TABLE 4. $Z-R$ relations during different rain events.

\begin{tabular}{lcccccccc}
\hline \hline & \multicolumn{2}{c}{ Convective } & & \multicolumn{2}{c}{ Transition } & & \multicolumn{2}{c}{ Stratiform } \\
\cline { 2 - 3 } Dates & $A$ & $b$ & & $A$ & $b$ & & $A$ & $b$ \\
\hline 17 May 1999 & 1466 & 1.05 & & 293 & 1.63 & & 733 & 1.14 \\
26 Aug 1999 & 352 & 1.24 & & 112 & 1.50 & & 562 & 0.97 \\
22 Jun 2000 & 129 & 1.58 & & 105 & 1.64 & & 490 & 1.24 \\
17 Jul 2000 & 520 & 1.02 & & 530 & 1.53 & & 604 & 1.38 \\
18 Aug 1999 & 1865 & 1.01 & & 856 & 1.29 & & - & - \\
28 Jul 2000 & 620 & 1.26 & & - & - & & - \\
21 Jun 2000 & - & - & & - & - & & 467 & 1.17 \\
\hline
\end{tabular}

to 3 March 1998 at Darwin, Australia. It is clear that even for each type of rain there is no distinct $Z-R$ relation. For example the coefficient $A$ in the convective rain is varying from 99 to 906 and exponent $\mathrm{b}$ is varying from 1.08 to 1.51 . Similarly for stratiform rain the values of the coefficient and exponent are found to be varying from 89 to 865 and 1.01 to 1.90 , respectively. These variations indicate that different microphysical processes are involved from system to system, which results in wide ranges of DSDs. It is also obvious from the reported results that the two extreme microphysical processes, that is, number controlled $(b \sim 1.0)$ and size controlled $(b \sim 1.80)$, occur both in convective as well as in stratiform rain.

The variability of DSDs during these three rain regimes can also be understood with the help of normalized intercept parameter $N_{0}^{*}$. The scatterplots for $N_{0}^{*}$ versus $R$ during convective, transition, and stratiform rain are shown in Figs. $8 \mathrm{a}, 8 \mathrm{~b}$, and $8 \mathrm{c}$, respectively. The values of the coefficient and the exponent of fitted power law are shown in the respective figure panels. The coefficients and exponents are in the order of $\mathrm{T}>\mathrm{C}>\mathrm{S}$ and $\mathrm{S}>\mathrm{T}>\mathrm{C}$, respectively. The $N_{0}^{*}-R$ relations shows distinct characteristics for the three types of rain. The smallest value of the coefficient of $N_{0}^{*}-R$ relation during stratiform rain indicates the presence of larger mean raindrops $\left(N_{0}^{*}\right.$ proportional to $\left.1 / D_{m}\right)$ compared to convective and transition rain. During stratiform rain, the maximum value of the exponent signifies the maximum sensitivity of $N_{0}^{*}$ with respect to $R$. It indicates that, by virtue of the least sensitivity of $D_{m}$ with respect to $R$ during stratiform rain, the term $\mathrm{LWC} / D_{m}$ in the $N_{0}^{*}$ expression is not constant and therefore $R$ is directly proportional to LWC. The correlation coefficients during convective, transition, and stratiform rain are found to be $0.20,0.24$, and 0.46 , respectively. The maximum value of the correlation coefficient during stratiform rain for $N_{0}^{*}-R$ relative to convective and transition rain further signifies the maximum sensitivity of $N_{0}^{*}$ with respect to $R$ during stratiform rain. A similar result is also reported by Testud et al. (2001). They pointed out that, when no distinction is made between convective and stratiform rain, the correlation coefficient for $N_{0}^{*}-R$ is reported around 0.40 with an exponent value of 1.31 . However, after separating the convective and stratiform DSD spectra, the correlation coefficient reduced significantly for the convective, that is, almost to 0 , with a very small value of exponent. Whereas for the stratiform spectra the correlation coefficient is reduced to 0.22 , but the exponent increased to 2.48 .

\section{b. Case study for the variability of rain integral parameters with respect to different microphysical process in the convective and stratiform rain}

The comparison of the temporal variation of mean diameter as measured from the JWD and L-band wind profiler is carried out for different rain events. The temporal variation of $D_{m \text {,(profiler) }}$ and $D_{m,(J W D)}$ on 17-18 May, 26 August, 21-22 June, 22-23 June, and 18 August are shown in Figs. 9a, 9b, 9c, 9d, and 9e, respectively. The classification of the different types of rain, as proposed by Williams et al. (1995) and Testud et al. (2001), are also shown in the same figure. The overall error

TABLE 5. Z-R relations from other places.

\begin{tabular}{|c|c|c|c|c|c|c|c|}
\hline \multirow[b]{2}{*}{ Reference } & \multirow[b]{2}{*}{ Dates } & \multicolumn{2}{|c|}{ Convective } & \multicolumn{2}{|c|}{ Transition } & \multicolumn{2}{|c|}{ Stratiform } \\
\hline & & $A$ & $b$ & $A$ & $b$ & $A$ & $b$ \\
\hline Ulbrich and Atlas (2007) & 15 Oct 1998 & 906 & 1.13 & 310 & 1.46 & 280 & 1.46 \\
\hline Rao et al. (2001) & 3 Nov 1997 & 331 & 1.29 & 275 & 1.15 & 447 & 1.38 \\
\hline \multirow[t]{6}{*}{ Atlas et al. (1999) } & 10 Dec 1992 & 766 & 1.14 & 187 & 1.45 & 233 & 1.01 \\
\hline & 9 Dec 1992 & 99 & 1.47 & 165 & 1.34 & 252 & 1.61 \\
\hline & 17 Jan 1993 & 588 & 1.08 & 102 & 1.59 & 89 & 1.90 \\
\hline & & - & - & - & - & $279^{*}$ & 1.48 \\
\hline & 26 Jan 1993 & 334 & 1.19 & 147 & 1.34 & 278 & 1.44 \\
\hline & & - & - & - & - & $865^{*}$ & 1.08 \\
\hline Maki et al. (2001) & Combined events & 233 & 1.39 & 259 & 1.29 & 532 & 1.28 \\
\hline Rao et al. (2001) & Combined events & 178 & 1.51 & 162 & 1.44 & 251 & 1.51 \\
\hline
\end{tabular}

* Extended stratiform regime of the same event. 


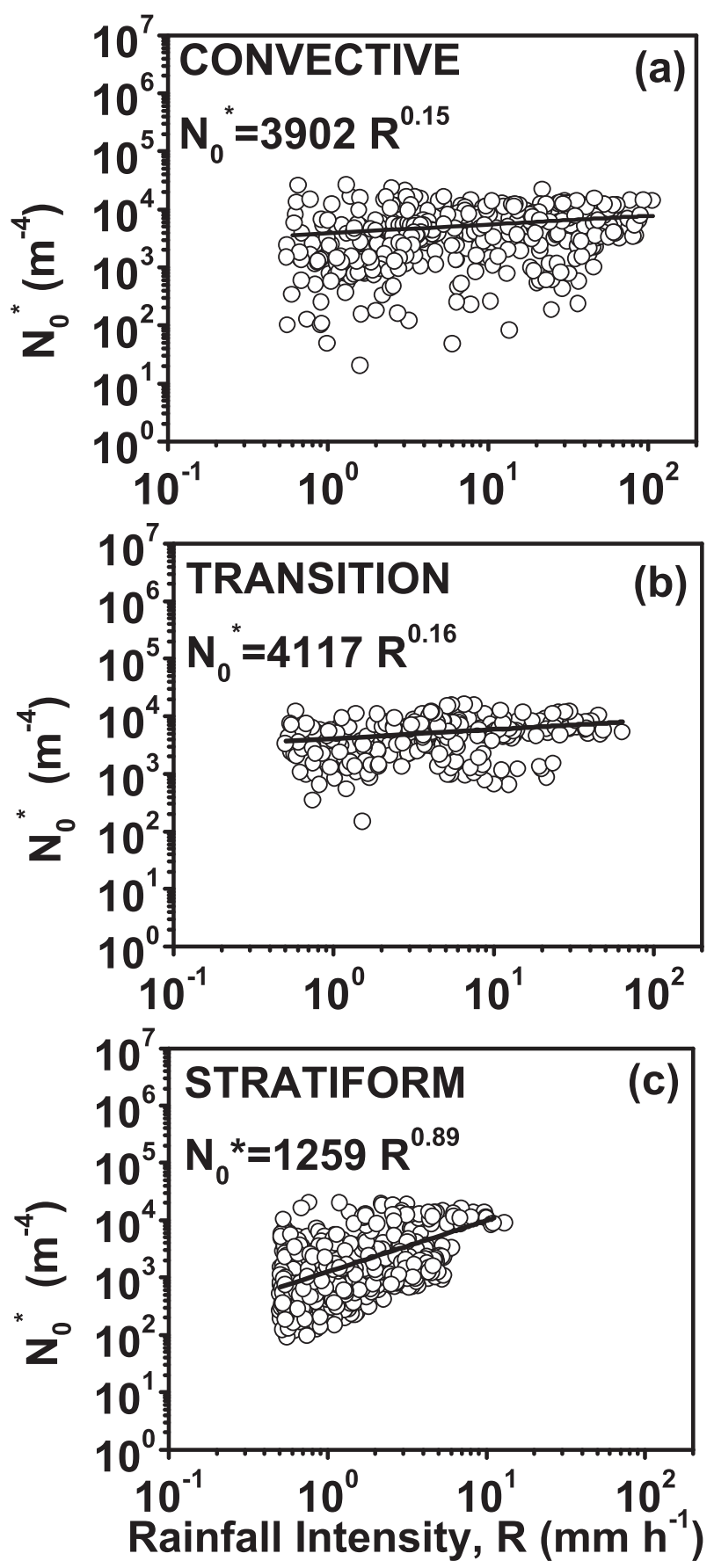

FIG. 8. As in Fig. 5, but for $N_{0}^{*}$ vs $R$.

statistics in terms of correlation coefficient and bias is provided in the respective figure panels. The biases are estimated with respect to JWD measurement. In all the cases the correlation coefficients are found to be $\geq 0.81$ and bias is found to be $\leq-0.73 \mathrm{~mm}$. The negative bias indicates that JWD measurements are underestimated with varying magnitudes relative to profiler measure- ments. The maximum bias is observed on 17-18 May (Fig. 9a). On this day the bias is quite significant during convective and stratiform rain relative to transition rain. The minimum bias is found to be $-0.15 \mathrm{~mm}$ on $21-22$ June. It is to be mentioned that on this day measurements are available for stratiform rain only. Similarly, the temporal variations of radar reflectivity factor $(\mathrm{dBZ})$ as measured from the JWD and profiler for the rain event on these five days are shown in Figs. 10a, 10b, $10 \mathrm{c}, 10 \mathrm{~d}$, and $10 \mathrm{e}$, respectively. The overall error statistics in terms of correlation coefficient and bias is provided in the respective figure panels. In all the cases, the correlation coefficients are found to be $\geq 0.80$ and bias is found to be $\leq-4.18 \mathrm{dBZ}$. The negative bias indicates that JWD measurements are underestimated compared to profiler measurements, though with varying magnitudes. The maximum bias of the value $-4.18 \mathrm{dBZ}$ is observed on 17-18 May (Fig. 10a) and the minimum of $-0.92 \mathrm{dBZ}$ is observed on 22-23 June (Fig. 10d). For the $\mathrm{dBZ}$ measurements, the correlation is better compared to mean diameter measurements. It is attributed to the calibration of the profiler with the JWD. The mean values of $D_{m}$ and $\mathrm{dBZ}$ along with their standard deviation during each regime for these five rain events are provided in Table 6 . In all the cases the convective rain is dominated by bigger raindrops relative to stratiform rain. The mean $D_{m}>2 \mathrm{~mm}$ is observed during all the convective regimes, except on 22-23 June where it is found to be $1.71 \mathrm{~mm}$. In the stratiform regimes the largest mean raindrop is found on 17-18 May and the minimum on 26 August. In both the situations, that is, convective and stratiform, there is no consistency in the proportionality of $D_{m}$ and $\mathrm{dB} Z$ values.

For better understanding of the variability of rain integral parameters, a detailed case study of some of the rain events is carried out during convective and stratiform rain. For the convective situations, two rain events on 18 August 1999 and 22 June 2000 are selected, where distinctly different characteristics of the studied parameters are observed. The variability of rain integral parameters during convective events is studied with the help of clear-air vertical velocity from VHF wind profiler. Similarly, stratiform rain events on 17-18 May 1999, 26 August 1999, and 23 June 2000 are selected where the distinct characteristics of rain parameters are observed. The stratiform rain events are studied with the help of the characteristics of the bright band as observed from the L-band wind profiler.

\section{1) Convective Rain}

The height-time contour plots of the vertical air velocity during rain on 18 August and 22 June are shown in Figs. 11a and 11b, respectively. On 18 August during 

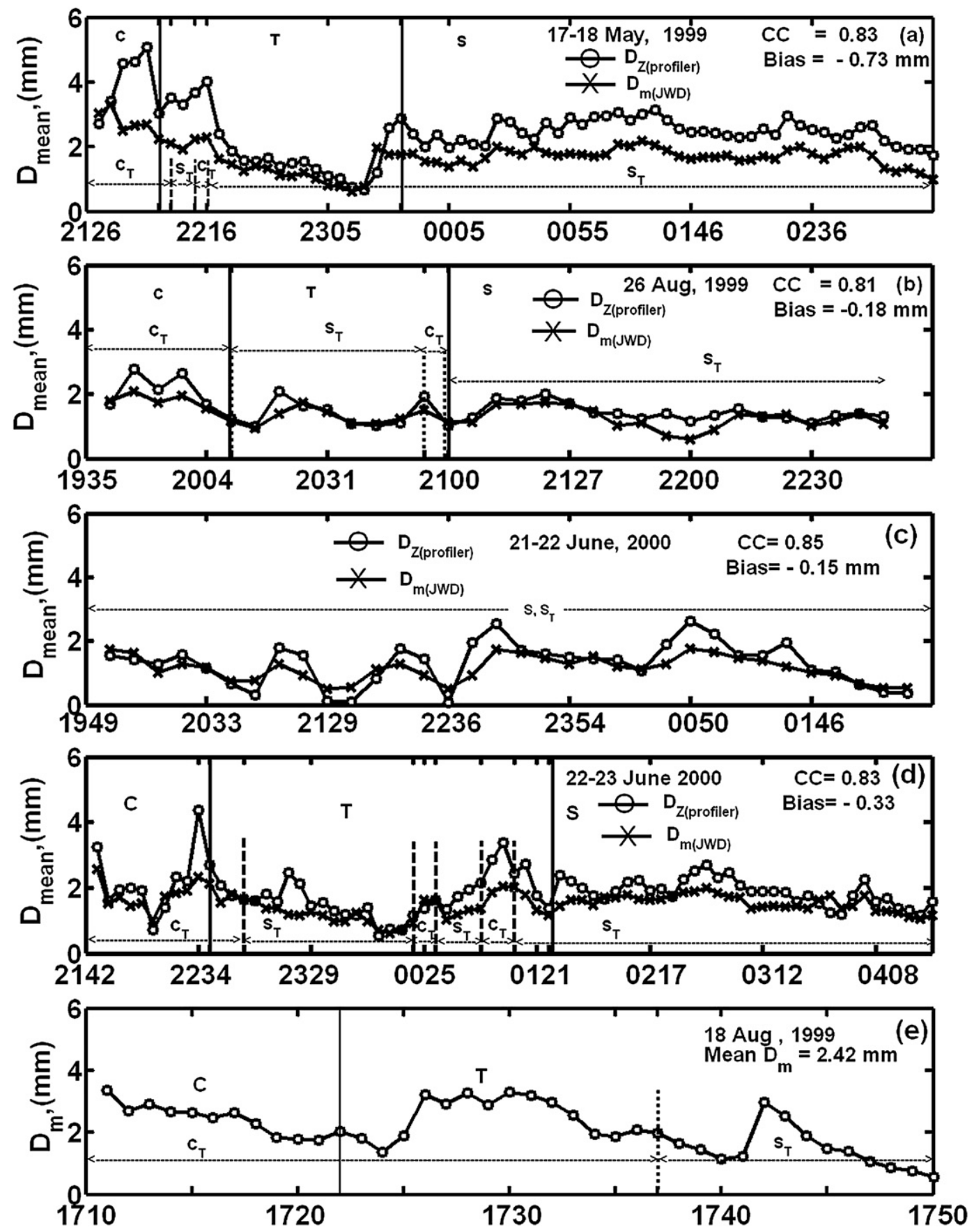

Time (Hrs)

FIG. 9. Temporal variation of mean raindrop diameter as measured by L-band profiler at $0.60 \mathrm{~km}$ and JWD at the ground for the rain event on (a) 17-18 May 1999, (b) 26 Aug 1999, (c) 21-22 Jun 2000, (d) 22-23 Jun 2000, and (e) 18 Aug 1999.

convective rain strong updrafts and downdrafts are observed. During the leading edge of the convective system strong updrafts of the magnitude of $2.5 \leq w \leq 8.22 \mathrm{~m} \mathrm{~s}^{-1}$ from the $3.2-5.10-\mathrm{km}$ height are observed. Thereafter at the trailing edge of the convective system downdrafts of moderate magnitude are observed from $\sim 4$ to $6 \mathrm{~km}$. On 22 June, at the initial stage of the rain event, the updrafts of strength $6 \mathrm{~m} \mathrm{~s}^{-1}$ are observed at around 4-6 km. At 

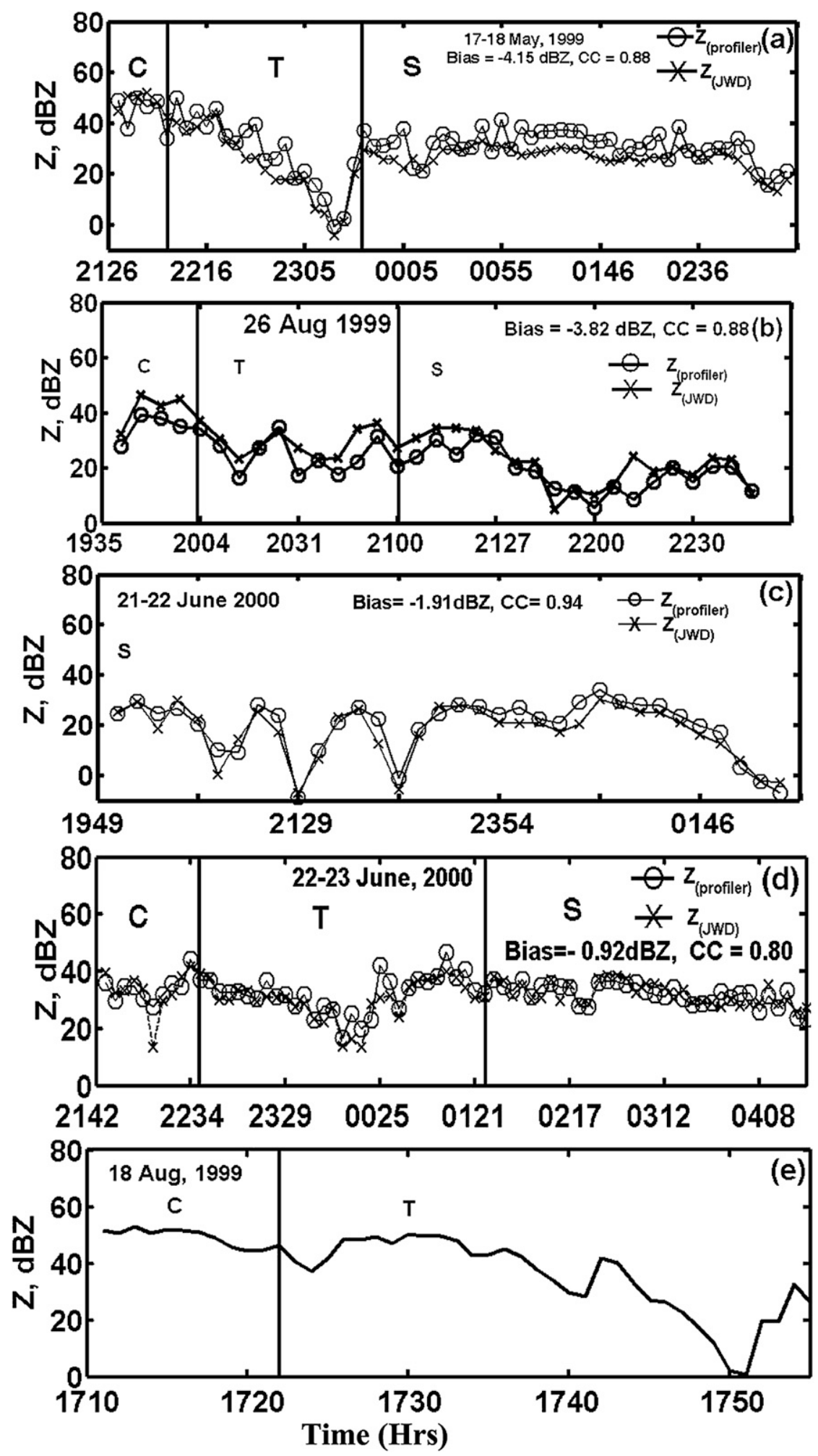

FIG. 10. As in Fig. 9, but for the radar reflectivity factor. 
TABLE 6. Rain integral parameters during convective, transition, and stratiform rain.

\begin{tabular}{|c|c|c|c|c|c|c|c|}
\hline \multirow[b]{2}{*}{ Date } & \multirow[b]{2}{*}{ Parameter } & \multicolumn{2}{|c|}{ Convective } & \multicolumn{2}{|c|}{ Transition } & \multicolumn{2}{|c|}{ Stratiform } \\
\hline & & Mean & Std dev & Mean & Std dev & Mean & Std dev \\
\hline \multirow[t]{2}{*}{ 17-18 May 1999} & $D_{m}(\mathrm{~mm})$ & 2.77 & 0.55 & 1.58 & 0.41 & 1.74 & 0.23 \\
\hline & $Z(\mathrm{~dB} Z)$ & 49 & 3 & 38 & 5 & 24 & 7 \\
\hline \multirow[t]{2}{*}{ 26-27 Aug 1999} & $D_{m}$ & 2.02 & 0.39 & 1.27 & 0.28 & 1.27 & 0.37 \\
\hline & $Z$ & 42 & 8 & 30 & 6 & 15 & 14 \\
\hline \multirow[t]{2}{*}{ 21-22 Jun 2000} & $D_{m}$ & - & - & - & - & 1.36 & 0.28 \\
\hline & $Z$ & - & - & - & - & 17 & 11 \\
\hline \multirow[t]{2}{*}{ 22-23 Jun 2000} & $D_{m}$ & 1.71 & 0.43 & 1.35 & 0.42 & 1.51 & 0.30 \\
\hline & $Z^{m}$ & 39 & 7 & 29 & 11 & 26 & 8 \\
\hline \multirow[t]{2}{*}{18 Aug 1999} & $D_{m}$ & 2.42 & 0.50 & 1.95 & 0.79 & - & - \\
\hline & $Z$ & 49 & 3 & 35 & 12 & - & - \\
\hline
\end{tabular}

around $2222 \mathrm{~h}$ downdrafts of magnitude $8.97 \mathrm{~m} \mathrm{~s}^{-1}$ are observed at 3-7 km. After that, up to around $2255 \mathrm{~h}$, downdrafts of magnitude $2.5 \leq w \leq 5.0 \mathrm{~m} \mathrm{~s}^{-1}$ are observed at the height of $3.0-5.5 \mathrm{~km}$. Both the events are of deep convective in nature as a strong vertical velocity core is seen at the upper heights, that is, up to $8 \mathrm{~km}$. Furthermore, the composite profiles of the vertical air motion during rain on these two days along with

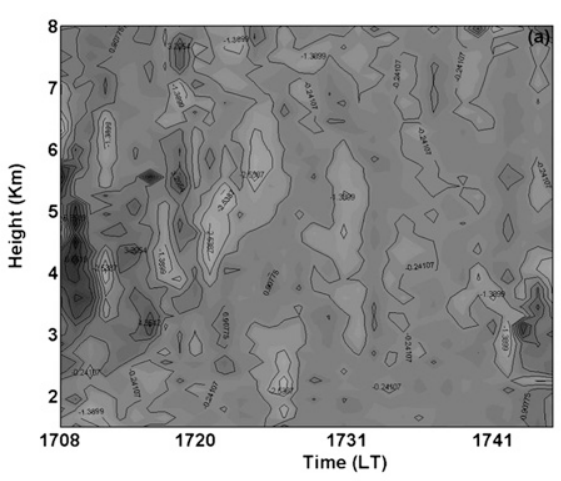

(a)

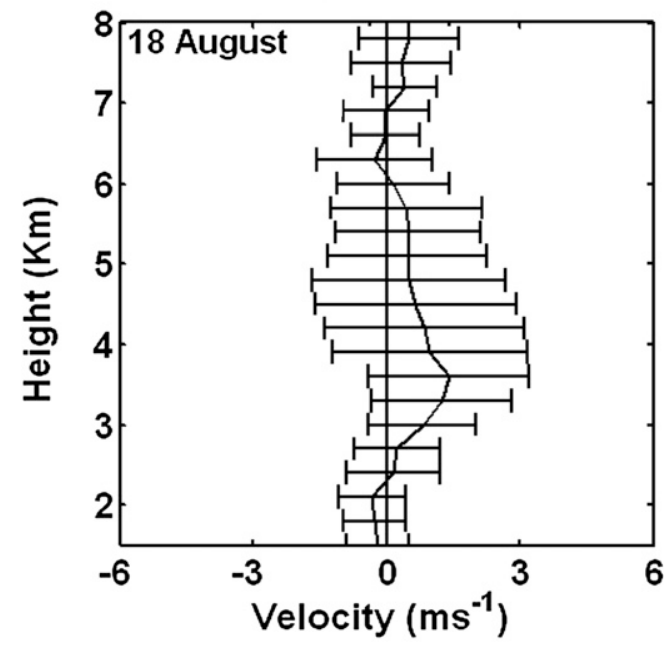

(c)
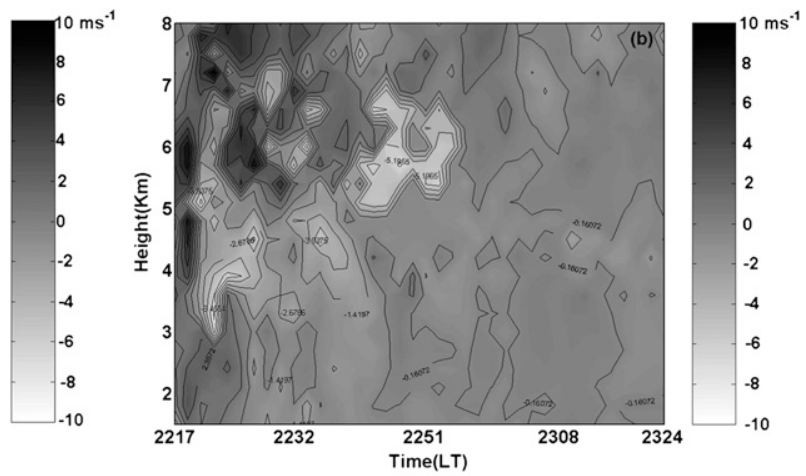

(b)

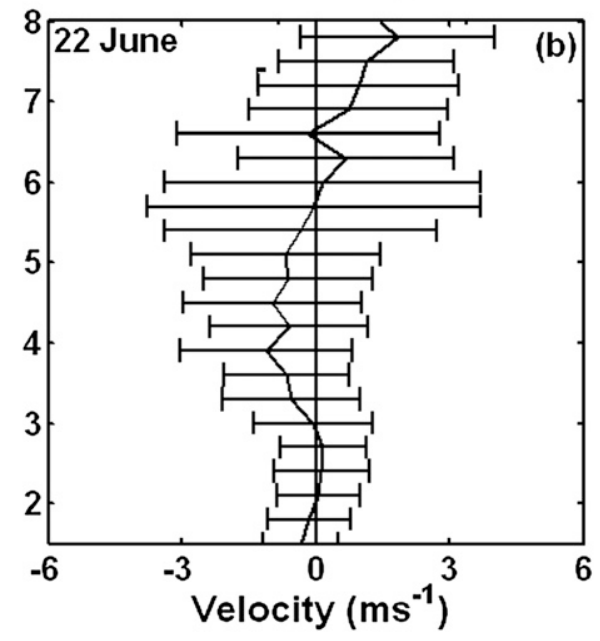

(d)

FIG. 11. Combined HTI and contour plots of clear-air vertical velocity from the VHF profiler on (a) 18 Aug 1999 and (b) 22 Jun 2000. The corresponding composite mean height profile of clear-air vertical velocity on (c) 18 Aug 1999 and (d) 22 Jun 2000. 
their deviations are shown in Figs. $11 \mathrm{c}$ and $11 \mathrm{~d}$, respectively. On 18 August, 8 profiles are averaged from 1708 to $1722 \mathrm{~h}$ Overall this event is dominated by mean updrafts of the magnitude of $0.10 \leq w \leq 2.31 \mathrm{~m} \mathrm{~s}^{-1}$ at the heights from 2.95 to $5.50 \mathrm{~km}$. On 22 June, 14 profiles are averaged from 2216 to $2238 \mathrm{~h}$ It is observed that the overall rain event is dominated by the mean downdrafts of the magnitude $0.1 \leq w \leq 1.11 \mathrm{~m} \mathrm{~s}^{-1}$ at the heights from 3 to $5.7 \mathrm{~km}$. On 18 August, the observations of the larger mean drops $D_{m}$ of $2.42 \mathrm{~mm}$ at the ground can be understood by the partitioning of raindrops by the updrafts, when the strong updrafts of the order of 5 to $8 \mathrm{~m} \mathrm{~s}^{-1}$ are observed. These updrafts partition the raindrops into small particles that rise and fall elsewhere and large ones that reach the surface in narrow distributions where the fall speed corresponds approximately to the updraft speed (Atlas and Williams 2003). The presence of downdraft in the lower height would decrease the residence time of raindrops in the atmosphere, in turn decreasing the collision time for raindrops, which further minimizes the formation of bigger drops. This may be one of the reasons for the smaller mean raindrops of $1.71 \mathrm{~mm}$ on 22 June.

\section{2) STRATIFORM RAIN}

The temporal variations of the vertical velocity gradient of the fall velocity of mean raindrops on 17-18 May 1999, 26 August 1999, and 23 June 2000 are shown in terms of contour plots in Figs. 12a, 12b, and 12c, respectively. On these days, by virtue of the vertical velocity gradient, the bright bands are observed at around $4-\mathrm{km}$ height with varying thickness and duration. It is observed that on 17-18 May the average thickness of the bright band is $703 \mathrm{~m}$ with a standard deviation of $179 \mathrm{~m}$. It is also observed that, at the core of the bright band, velocity gradients of $>10 \mathrm{~m} \mathrm{~s}^{-1} \mathrm{~km}^{-1}$ are present consistently for nearly $5 \mathrm{~h}$. On 26 August, the average thickness of the bright band is found to be $576 \mathrm{~m}$ with a standard deviation of $162 \mathrm{~m}$, but it is not very well developed and is of short duration. The velocity gradient $>10 \mathrm{~m} \mathrm{~s}^{-1} \mathrm{~km}^{-1}$ and the bright band are observed for around $20 \mathrm{~min}$ during $2100-2120 \mathrm{~h}$. After a break, again the bright band, with a velocity gradient of $8-12 \mathrm{~m} \mathrm{~s}^{-1} \mathrm{~km}^{-1}$, appeared for a short duration from 2211 to $2250 \mathrm{~h}$ for a time period of around $40 \mathrm{~min}$. On 23 June the thickness of the bright band is found to be $601 \mathrm{~m}$ with a standard deviation of $181 \mathrm{~m}$. The velocity gradient of $>10 \mathrm{~m} \mathrm{~s}^{-1} \mathrm{~km}^{-1}$ is observed for around $3 \frac{1}{2} \mathrm{~h}$ during $0121-0350 \mathrm{~h}$. Overall it is well developed compared to 26 August. On 17-18 May the presence of bigger mean raindrops of the value of $1.72 \mathrm{~mm}$ are observed, whereas on 26 August and 23 June it is found to be of 1.26 and $1.56 \mathrm{~mm}$, respectively. The bigger mean raindrops on 17-18 May and
23 June are found to be associated with strong bright band and persisted for a longer duration, whereas smaller mean raindrops on 26 August are found to be associated with a weak bright band of shorter duration. Therefore, the variability of the $D_{m}$ in stratiform rain can be understood by studying the characteristics of the bright band. Huggel et al. (1996) also studied the relationship between the strength of bright band and the characteristics of DSD. They found that steep spectra with many small drops are associated with small value of $\Delta Z_{e}$ (where $\Delta Z_{e}$ is defined as ratio between the maximum reflectivity in the bright band and its minimum in a layer just below the melting layer), whereas flat spectra with relatively few small drops and with large drops exhibit a welldefined bright band with a large $\Delta Z_{e}$.

\section{c. The $Z / D_{m}-R$ relation and its application in rain retrieval}

As a result of these variations in rain integral parameters, even for each type of rain, there are constraints to propose a generalized empirical relation between the rain integral parameters, that is, $D_{m}-R$ or $Z-R$. In convective rain these constraints are due to different prevailing microphysical process by virtue of different physical and dynamical natures of storms that governed the characteristics of DSDs, that is, coalescence, breakup, evaporation, strength of updrafts-downdrafts, and sorting of drops by drafts (Rosenfeld and Ulbrich 2003). Even for stratiform rain, which is considered to consist of homogeneous and uniform rain, there is significant variation in the DSDs because of the variation of the thickness of the bright band. Therefore it is assumed that the different microphysical processes are appropriately manifested in the drop size distribution and thereby on mean drop diameter $D_{m}$. As the empirical relations involving a single measured parameter may not give desired rain retrieval accuracy (Testud et al. 2001), one more parameter in term of $D_{m}$, which is very much a direct indicator of microphysical processes, is considered in the new empirical relation. In the present study the $Z$ has been normalized by the $D_{m}$. The empirical relations are found out by fitting the power-law equations to $Z / D_{m}-R$ scatterplots for each rain type. The scatterplots of $Z / D_{m}$ versus $R$ for total data during convective, transition, and stratiform rain are shown in Figs. 13a, 13b, and $13 \mathrm{c}$, respectively. The values of the coefficients and exponents of the fitted power law are provided in the respective figure panels. The coefficients and exponent of these relations are in the order of $\mathrm{S}>\mathrm{C}>\mathrm{T}$ and $\mathrm{T}>$ $\mathrm{C}>\mathrm{S}$, respectively. The values of the coefficients and exponents of the power law for individual rain events are provided in Table 7. Furthermore, the correlation 

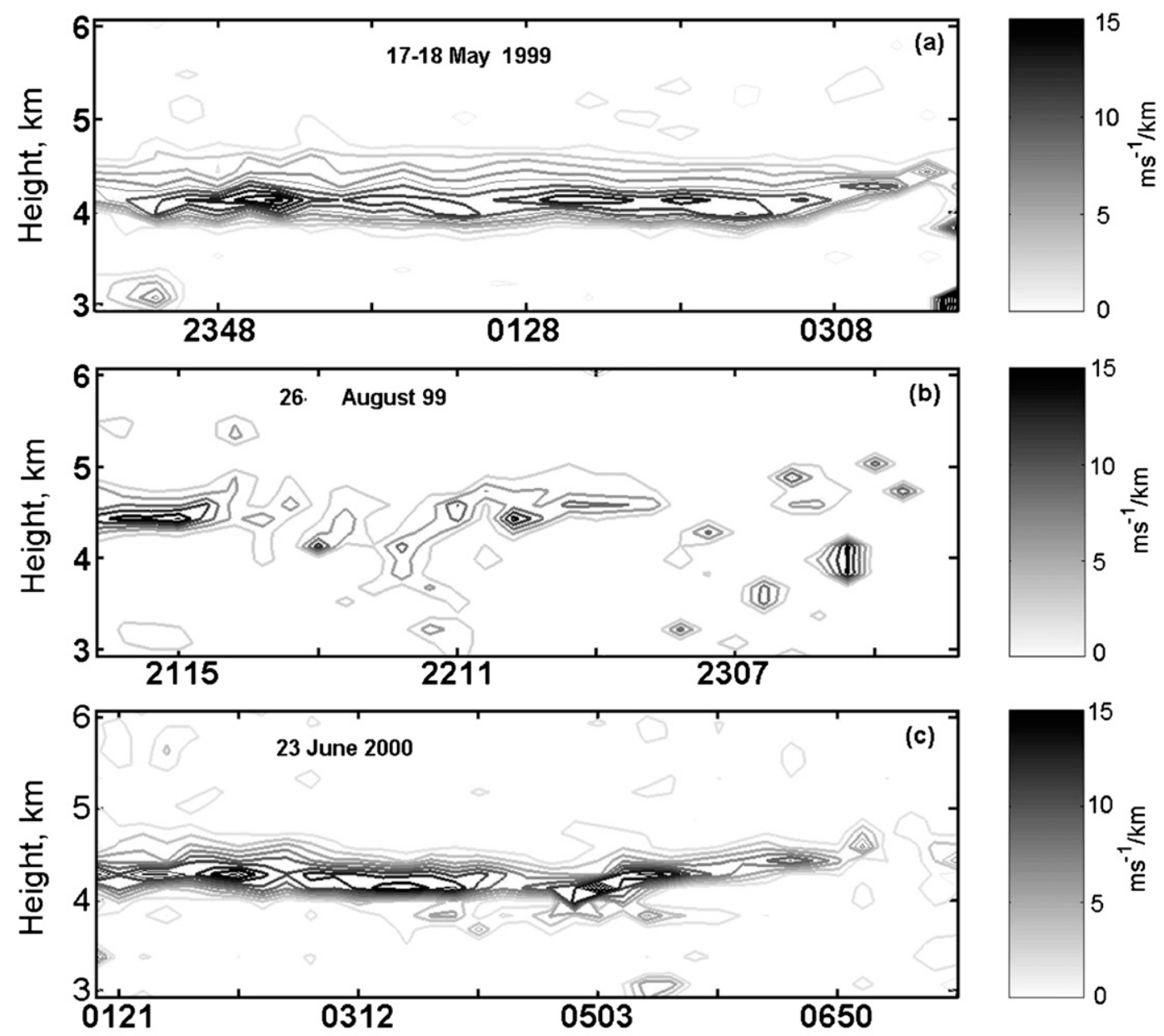

Time ( Hrs)

FIG. 12. Contour plots for temporal variation of DVG during stratiform rain on (a) 17-18 May 1999, (b) 26 Aug 1999, and (c) 23 Jun 2000.

coefficients during each type of rain for all developed empirical relations are provided in Table 8 . It is observed that, for each type of rain, the correlation coefficients are in the order of $Z / D_{m}-R>Z-R>D_{m}-Z>D_{m}-R$. It is also observed that, during different types of rain, there is a systematic variation in the exponent for each relation. They are in the order of $\mathrm{T}>\mathrm{C}>\mathrm{S}$. As the overall correlation coefficient is maximum for the $Z / D_{m}-R$ relations, thereby signifying the better estimation of rain intensity by using the $Z / D_{m}-R$ relation compared to other relations. The $Z / D_{m}-R$ relation will be suitable for estimating the rainfall intensity by scanning polarimetric radar or vertically looking profiler radars where multivariable measurements such as $Z$ and $D_{m}$ are possible to measure.

The comparison of the rain intensity as estimated from $Z-R$ and $Z / D_{m}-R$ relations, during each type of rain, is carried out on 22 and 23 June 2000. For this purpose, $Z$ and $D_{m}$ are estimated by the DSD spectra from the JWD measurements and the rain retrieval is validated with the observed rain rate by JWD. The temporal variation of estimated rain intensity from $Z-R$ and $Z / D_{m}-R$ relations and its comparison with observed values during convective, transition, and stratiform rain are shown in Figs. 14a, 14b, and 14c, respectively. The error statistics of this retrieval in terms of correlation coefficient and rmse is provided in the respective figure panels. For each type of rain, rmse is reduced and correlation coefficient is increased for the $Z / D_{m}-R$ relation compared to the $Z-R$ relation. The intercomparisons of rain retrieval by $Z-R$ and $Z / D_{m}-R$ relations for the other selected rain events are provided in Table 9. From these error statistics, it is very clear that there is an 

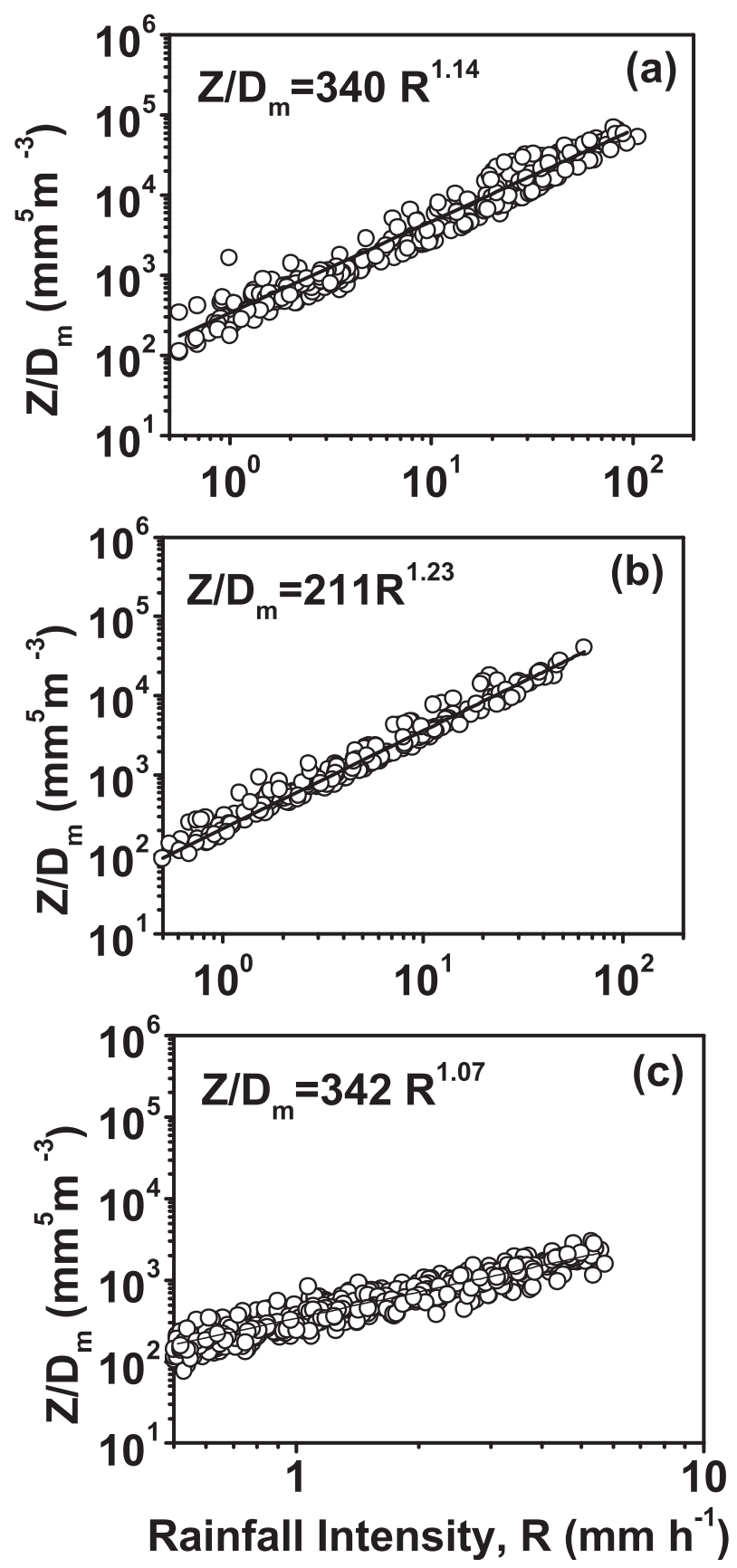

FIG. 13. Scatterplots for $Z / D_{m}$ vs $R$ for all the selected rain events during (a) convective, (b) transition, and (c) stratiform rain.

improvement in rain retrieval by using the $Z / D_{m}-R$ relation compared to conventional $Z-R$ relation. The rmse for rain retrieval even found to reduce by $46 \%$ in some events irrespective of types of rain. The minimum reduction in rmse is found to be by $19 \%$. Huggel et al. (1996) reported that the rmse in rain retrieval is reduced by $20 \%-40 \%$ relative to conventional $Z-R$ relation by using the dual parameter, $Z$ and $\Delta Z_{e}$. Testud et al.
TABLE 7. $Z / D_{m}-R$ relations for different storms.

\begin{tabular}{lcccccccc}
\hline \hline & \multicolumn{2}{c}{ Convective } & & \multicolumn{2}{c}{ Transition } & & \multicolumn{2}{c}{ Stratiform } \\
\cline { 2 - 3 } \multicolumn{1}{c}{ Dates } & $A^{\prime}$ & $b^{\prime}$ & & $A^{\prime}$ & $b^{\prime}$ & & $A^{\prime}$ & $b^{\prime}$ \\
\hline 17 May 1999 & 616 & 1.02 & & 202 & 1.43 & & 395 & 1.09 \\
26 Aug 1999 & 255 & 1.14 & & 132 & 1.28 & & 337 & 0.99 \\
22 Jun 2000 & 132 & 1.36 & & 138 & 1.35 & & 316 & 1.16 \\
17 Jul 2000 & 309 & 1.00 & & 328 & 1.33 & & 352 & 1.23 \\
18 Aug 1999 & 714 & 1.00 & & 458 & 1.16 & & \\
28 Jul 2000 & 276 & 1.22 & & & & \\
21 Jun 2000 & & & & & 301 & 1.10 \\
\hline
\end{tabular}

(2001) also found that there is a significant improvement in the error statistics of the rain retrieval with the normalized approach. They reported that by taking into account the normalization by $N_{0}^{*}$ (for all types of data) the correlation coefficient for rain retrieval is increased from 0.84 to 0.98 and the standard deviation parameter is reduced from 0.26 to 0.12 .

\section{Conclusions}

In the present study the characteristics of rain integral parameters are studied at NARL, Gadanki, with the help of JWD, L-band, and VHF wind profilers during tropical convective, transition, and stratiform rain. The precipitating systems are classified with the help of the L-band wind profiler by using the spectral moment parameters of Doppler spectrum. The rain integral parameters are estimated from the JWD and the L-band wind profiler. The clear-air vertical velocities are estimated from the VHF profiler and are utilized to study the updrafts/downdrafts during the convective rain. Reasonably good agreement is found between JWD and L-band profiler measurements. Furthermore, the studied characteristics of rain integral parameters are utilized to develop the dual parameter empirical relations to retrieve the rain rate. From the present study the main conclusions are as follows:

1) For $R \leq 10 \mathrm{~mm} \mathrm{~h}^{-1}$, the stratiform rain events are associated with bigger mean raindrops relative to convective and transition rain. For $R>10 \mathrm{~mm} \mathrm{~h}^{-1}$, the convective rain is associated with bigger mean raindrops relative to stratiform and transition rain.

TABLE 8. Correlation coefficients for different empirical relations.

\begin{tabular}{lccc}
\hline \hline & \multicolumn{3}{c}{ Correlation coef } \\
\cline { 2 - 4 } Relation & Convective & Transition & Stratiform \\
\hline$D_{m}-R$ & 0.65 & 0.75 & 0.20 \\
$D_{m}-Z$ & 0.84 & 0.88 & 0.60 \\
$Z-R$ & 0.91 & 0.95 & 0.88 \\
$Z / D_{m}-R$ & 0.96 & 0.97 & 0.94 \\
\hline
\end{tabular}




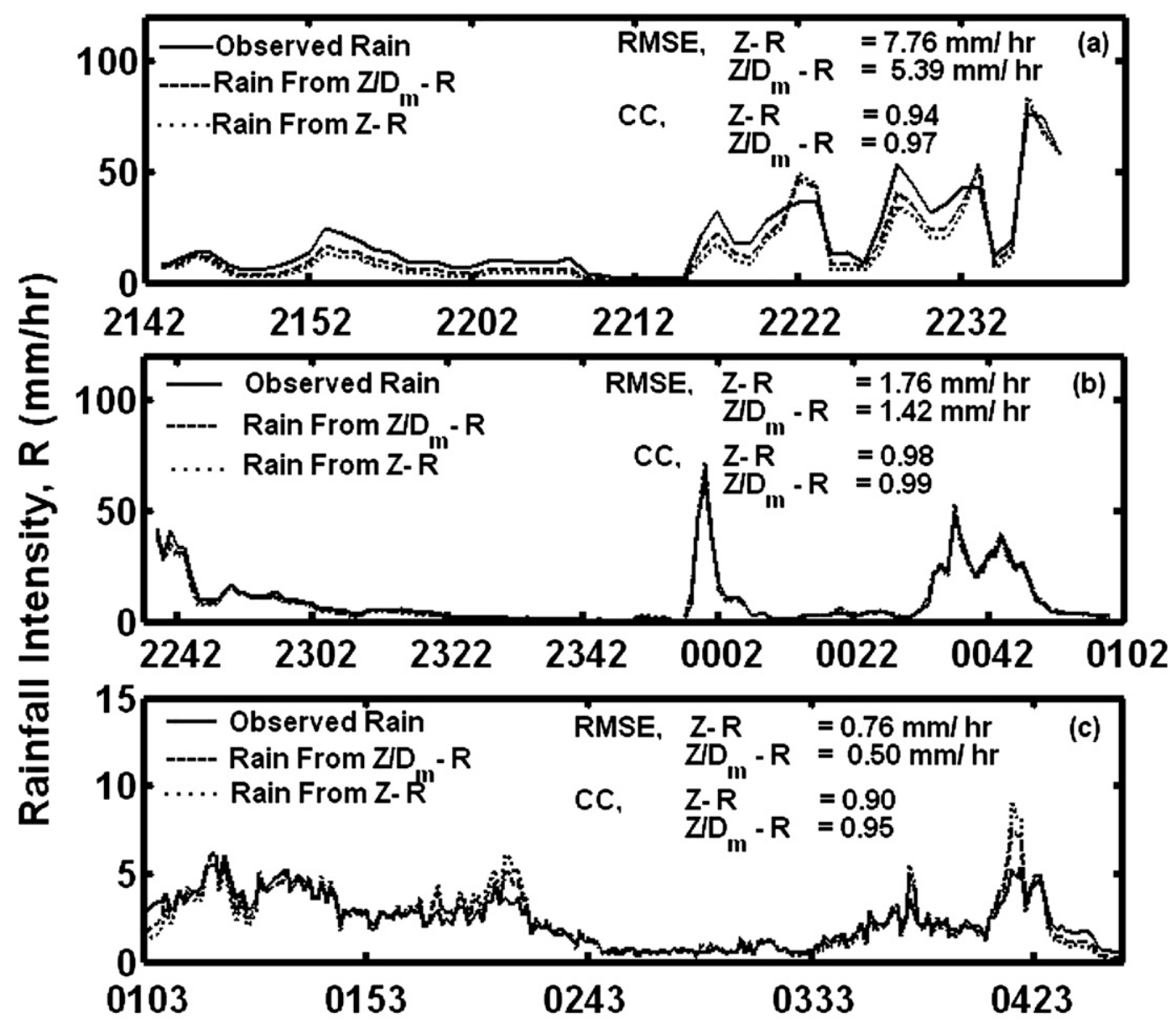

\section{Time (Hrs)}

FIG. 14. Temporal variation of estimated rain intensity by using $Z-R, Z / D_{m}-R$ relations and JWD during (a) convective, (b) transition, and (c) stratiform rain on 22-23 Jun 2000.

2) The typical variations of coefficient and exponent for various empirical power-law relations are found to be as follows:

$$
D_{m}-R, D_{m}-Z, \quad \text { and } \quad Z / D_{m}-R \text { : }
$$

coefficient: stratiform $>$ convective $>$ transition; exponent: transition $>$ convective $>$ stratiform.

$$
Z-R \text { : }
$$

coefficient: convective $>$ stratiform $>$ transition; exponent: transition $>$ convective $>$ stratiform.

For all the above developed empirical relations, it is observed that the exponent values have systematic variations during the three types of rain. For each relation, the maximum value of exponent is found for transition rain, thereby signifying the maximum sensitivity of these rain integral parameters with respect to $R$ during the transition type of rain.

3) The variations of the coefficient and exponent for the $N_{0}^{*}-R$ relation are as follows:

$$
N_{0}^{*}-R:
$$

coefficient: convective $>$ transition $>$ stratiform; exponent: stratiform $>$ transition $>$ convective.

The maximum value of the exponent during stratiform rain signifies the maximum sensitivity of $N_{0}^{*}$ with respect to rain rate. It is attributed to the least sensitivity of $D_{m}$ with respect to $R$ during stratiform rain, therefore making the $N_{0}^{*}$ (which is $\left.\sim \mathrm{LWC} / D_{m}\right)$ directly proportional to $R$.

4) From event to event there is no systematic variation in the values of the coefficient and exponent of $Z-R$ 
TABLE 9. Intercomparison of rain retrieval by $Z-R$ and $Z / D_{m}-R$ relations; C: convective, T: transition, S: stratiform, CC: correlation coefficient.

\begin{tabular}{|c|c|c|c|c|c|c|}
\hline \multirow{2}{*}{$\frac{\text { Dates }}{17 \text { May } 1999}$} & \multirow{2}{*}{$\frac{\text { Types of rain }}{\mathrm{C}}$} & \multicolumn{2}{|c|}{$\frac{Z-R \text { rmse }\left(E_{1}\right) \mathrm{CC}}{\left(\mathrm{mm} \mathrm{h}^{-1}\right)}$} & \multicolumn{2}{|c|}{$\frac{Z / D_{m}-R \text { rmse }\left(E_{2}\right) \mathrm{CC}}{\left(\mathrm{mm} \mathrm{h}^{-1}\right)}$} & \multirow{2}{*}{$\frac{\frac{\text { Reduction in rmse }}{\left[\left(E_{1}-E_{2}\right) / E_{1}\right] \times 100(\%)}}{35}$} \\
\hline & & 12.66 & 0.88 & 8.29 & 0.95 & \\
\hline & $\mathrm{T}$ & 7.35 & 0.98 & 5.02 & 0.98 & 32 \\
\hline & $\mathrm{S}$ & 0.44 & 0.93 & 0.24 & 0.96 & 45 \\
\hline \multirow[t]{3}{*}{26 Aug 1999} & $\mathrm{C}$ & 14.68 & 0.97 & 10.17 & 0.98 & 31 \\
\hline & $\mathrm{T}$ & 3.49 & 0.98 & 2.51 & 0.99 & 28 \\
\hline & $\mathrm{S}$ & 1.05 & 0.85 & 0.75 & 0.93 & 29 \\
\hline \multirow[t]{3}{*}{22 Jun 2000} & $\mathrm{C}$ & 7.76 & 0.94 & 5.39 & 0.97 & 31 \\
\hline & $\mathrm{T}$ & 1.76 & 0.98 & 1.42 & 0.99 & 19 \\
\hline & $\mathrm{S}$ & 0.76 & 0.90 & 0.50 & 0.95 & 34 \\
\hline \multirow[t]{3}{*}{17 Jul 2000} & $\mathrm{C}$ & 3.43 & 0.88 & 2.42 & 0.95 & 29 \\
\hline & $\mathrm{T}$ & 0.13 & 0.93 & 0.07 & 0.95 & 46 \\
\hline & $\mathrm{S}$ & 0.06 & 0.94 & 0.04 & 0.96 & 33 \\
\hline $28 \mathrm{Jul} 2000$ & $\mathrm{C}$ & 10.93 & 0.79 & 5.92 & 0.91 & 46 \\
\hline \multirow[t]{2}{*}{18 Aug 1999} & $\mathrm{C}$ & 18.57 & 0.87 & 12.00 & 0.95 & 35 \\
\hline & $\mathrm{T}$ & 5.64 & 0.91 & 4.14 & 0.95 & 36 \\
\hline 21 Jun 2000 & $\mathrm{~s}$ & 2.01 & 0.81 & 1.36 & 0.89 & 32 \\
\hline
\end{tabular}

relations, except for transition rain, where the coefficient is always at a minimum and the exponent is at a maximum.

5) It is observed that convective and stratiform rain events are predominantly number controlled and transition rains are size controlled.

6) During convective rain, the bigger mean raindrops are found during the presence of strong updrafts relative to the situation when it is dominated by downdrafts. During stratiform rain the bigger mean raindrops are found to be associated with the higher mean thickness of the bright band and strong velocity gradient.

7) The correlation coefficients for different empirical relations are in the order of $Z / D_{m}-R>Z-R>D_{m}-Z>$ $D_{m}-R$. From these observations, it is concluded that, relatively, $D_{m}$ and $R$ are the least dependent on each other. During different types of rain, the correlations, for each relation, are found in the order of $\mathrm{T}>\mathrm{C}>\mathrm{S}$.

8) For the rain-rate retrieval, the $Z / D_{m}-R$, empirical relations are proposed during convective, transition, and stratiform rain. Significant improvement is observed in rain retrieval by using these relations relative to the conventional $Z-R$ relations. For different rain events, the rmse of rain retrieval is reduced by $29 \%-46 \%$ during convective rain, $19 \%-$ $46 \%$ during transition rain, and $29 \%-45 \%$ during stratiform rain. However, the effective improvement in using $Z / D_{m}$ versus $R$ instead of a $Z$ versus $R$ scheme depends on how accurately $D_{m}$ can be measured. Also $D_{m}$ has to be measured at each radar point otherwise the scheme has to be tested for an event mean $D_{m}$. Currently the accuracy in $D_{m}$ deduced from operation measurements is not sufficient to improve significantly $R$ estimation from $Z / D_{m}$ versus $R$ scheme.

Acknowledgments. The present work is carried out under the ADCOS fellowship program from the Department of Space (DOS), Government of India. The authors thank the director, NARL, and the coordinator, the SVU-UGC center for MST Radar Applications, for providing the necessary support to conduct the experiments at the radar site and subsequent data analysis. The authors also acknowledge the support of the engineers at NARL Gadanki during the time of the experiments. The L-band wind profiler and JWD at NARL Gadanki have been installed under Indo-Japan Collaboration, between DOS/NARL, India, and MOPT/CRL, Japan.

\section{REFERENCES}

Atlas, D., and C. W. Ulbrich, 1977: Path- and area-integrated rainfall measurement by microwave attenuation in the $1-3 \mathrm{~cm}$ band. J. Appl. Meteor., 16, 1322-1331.

— , and C. R. Williams, 2003: The anatomy of a continental tropical convective storm. J. Atmos. Sci., 60, 3-15.

— , and C. Ulbrich, 2006: Drop size spectra and integral remote sensing parameters in the transition from convective to stratiform rain. Geophys. Res. Lett., 33, L16803, doi:10.1029/ 2006 GL026824.

_ R. C. Srivastava, and R. S. Sekhon, 1973: Doppler radar characteristics of precipitation at vertical incidence. Rev. Geophys., 11, 1-35. 
— C. W. Ulbrich, F. D. Marks Jr., E. Amitai, and C. R. Williams, 1999: Systematic variation of drop size and radar-rainfall relations. J. Geophys. Res., 104, 6155-6169.

—, D. Rosenfield, D. Short, R. A. Black, E. Amitai, P. T. Willis, and C. E. Samsury, 2000: Partitioning tropical oceanic convective and stratiform rain by draft strength. J. Geophys. Res., 105, 2259-2267.

Balsley, B. B., W. L. Ecklund, D. A. Carter, A. C. Riddle, and K. S. Gage, 1988: Average vertical motions in the tropical atmosphere observed by a radar wind profiler on Pohnpei $\left(7^{\circ} \mathrm{N}\right.$ latitude, $157^{\circ} \mathrm{E}$ longitude). J. Atmos. Sci., 45, 396-405.

Biggerstaff, M. I., and S. A. Listemma, 2000: An improved scheme for convective stratiform echo classification using radar reflectivity. J. Appl. Meteor., 39, 2129-2148.

Cifelli, R., and S. A. Rutledge, 1994: Vertical motion structure in maritime continent mesoscale convective systems: Results from a 50-MHz profiler. J. Atmos. Sci., 51, 2631-2652.

Doviak, R. J., 1983: A survey of radar rain measurement techniques. J. Climate Appl. Meteor., 22, 832-849.

Gossard, E. E., 1988: Measuring drop-size distributions in clouds with a clear-air-sensing Doppler radar. J. Atmos. Oceanic Technol., 5, 640-649.

Gunn, R., and G. D. Kinzer, 1949: The terminal velocity of fall for water droplets in stagnant air. J. Meteor., 6, 233-248.

Hong, Y. C., C. D. Kummerow, and W. S. Olson, 1999: Separation of convective and stratiform precipitation using microwave brightness temperature. J. Appl. Meteor., 38, 1195-1213.

Huggel, A. W., W. Schmid, and A. Waldvogel, 1996: Raindrop size distributions and the radar bright band. J. Appl. Meteor., 35, 1688-1701.

Jameson, A. R., 1991: The effect of drop size distribution variability on radiometric estimation of rainfall rates for frequencies from 3 to $10 \mathrm{GHz}$. J. Appl. Meteor., 30, 1025-1033.

Jones, D. M. A., 1959: The shape of raindrops. J. Meteor., 16, 504-510.

Joss, J., and E. G. Gori, 1978: Shape of raindrop size distributions. J. Appl. Meteor., 17, 1054-1061.

Kirankumar, N. V. P., T. N. Rao, B. Radhakrishna, and D. N. Rao, 2008: Statistical characteristics of raindrop size distribution in southwest monsoon season. J. Appl. Meteor. Climatol., 47, $576-590$.

Kishore, K. K., A. R. Jain, and D. N. Rao, 2005: VHF/UHF radar observations of tropical mesoscale convective systems over southern India. Ann. Geophys., 23, 1673-1683.

Konwar, M., D. K. Sarma, S. Sharma, U. K. De, S. Pal, and J. Das, 2008: Estimation of rain parameters from the spectral moments of L-band wind profiler by using Multilayer Perceptron Network model. Indian J. Radio Space Phys., 37, 341-352.

Maki, M., T. D. Keenan, Y. Sasaki, and K. Nakamura, 2001: Characteristics of the raindrop size distribution in tropical continental squall lines observed in Darwin, Australia. J. Appl. Meteor., 40, 1393-1412.

Marshall, J. S., and W. M. Palmer, 1948: The distribution of raindrops with size. J. Meteor., 5, 165-166.

Rajopadhyaya, D. K., P. T. May, R. C. Cifelli, S. K. Avery, C. R. Williams, W. L. Ecklund, and K. S. Gage, 1998: The effect of vertical air motions on rain rates and median volume diameter determined from combined UHF and VHF wind profiler measurements and comparisons with rain gauge measurements. J. Atmos. Oceanic Technol., 15, 1306-1319.

—, S. K. Avery, P. T. May, and R. C. Cifelli, 1999: Comparison of precipitation estimation using single- and dual-frequency wind profilers: Simulations and experimental results. J. Atmos. Oceanic Technol., 16, 165-173.

Ralph, F. M., 1995: Using radar-measured radial vertical velocities to distinguish precipitation scattering from clear-air scattering. J. Atmos. Oceanic Technol., 12, 257-267.

_, P. J. Neiman, D. W. van de Kamp, and D. C. Law, 1995: Using spectral moment data from NOAA's 404-MHz radar wind profilers to observe precipitation. Bull. Amer. Meteor. Soc., 76, 1717-1739.

- — , and D. Ruffieux, 1996: Precipitation identification from radar wind profiler spectral moment data: Vertical velocity histograms, velocity variance, and signal powervertical velocity correlations. J. Atmos. Oceanic Technol., 13, $545-559$.

Rao, T. N., D. N. Rao, and S. Raghavan, 1999: Tropical precipitating system observed with Indian MST radar. Radio Sci., 34, $1125-1139$

,,-- K. Mohan, and S. Raghavan, 2001: Classification of tropical precipitating systems and associated $Z-R$ relationships. J. Geophys. Res., 106, 17 699-17 711.

Reddy, K. K., and T. Kozu, 2003: Measurement of rain drop size distribution over Gadanki during south-west and north-east monsoon. Indian J. Radio Space Phys., 32, 286-295.

Rosenfeld, D., and C. W. Ulbrich, 2003: Cloud microphysical properties, processes, and rainfall estimation opportunities. Radar and Atmospheric Science: A Collection of Essays in Honor of David Atlas, Meteor. Monogr., No. 52, Amer. Meteor. Soc., 237-258.

Sauvageot, H., and J. P. Lacaux, 1995: The shape of averaged drop size distributions. J. Atmos. Sci., 52, 1070-1083.

Sharma, S., D. K. Sarma, M. Konwar, J. Das, and A. R. Jain, 2008: Retrieval of rain drop size distribution from the L-band and VHF wind profilers during convective and stratiform rain. Indian J. Radio Space Phys., 37, 185-196.

Smith, J. A., and W. F. Krajewski, 1993: A modeling study of rainfall rate-reflectivity relationships. Water Resour. Res., 29, 2505-2514.

Steiner, M., R. A. Houze Jr., and S. E. Yuter, 1995: Climatological characterization of three-dimensional storm structure from operational radar and rain gauge data. J. Appl. Meteor., 34, 1978-2007.

_ J. A. Smith, and R. Uijlenhoet, 2004: A microphysical interpretation of radar reflectivity-rain rate relationships. J. Atmos. Sci., 61, 1114-1131.

Stewart, R. E., J. D. Marwitz, J. C. Pace, and R. E. Carbone, 1984: Characteristics through the melting layer of stratiform clouds. J. Atmos. Sci., 41, 3227-3237.

Testud, J., S. Oury, R. A. Black, P. Amayenc, and X. Dou, 2001: The concept of "normalized" distribution to describe raindrop spectra: A tool for cloud physics and cloud remote sensing. J. Appl. Meteor., 40, 1118-1140.

Tokay, A., and D. A. Short, 1996: Evidence from tropical raindrop spectra of the origin of the rain from stratiform versus convective clouds. J. Appl. Meteor., 35, 506-531.

C. R. Williams, W. L. Ecklund, and K. S. Gage, 1999: Tropical rainfall associated with convective and stratiform clouds: Intercomparison of disdrometer and profiler measurement. J. Appl. Meteor., 38, 302-320.

— A. Kruger, and W. F. Krajewski, 2001: Comparison of drop size distribution measurements by impact and optical disdrometers. J. Appl. Meteor., 40, 2083-2097.

, D. B. Wolff, K. R. Wolff, and P. Bashor, 2003: Rain gauge and disdrometer measurements during the Keys Area 
Microphysics Project (KAMP). J. Atmos. Oceanic Technol., 20, 1460-1477.

Ulbrich, C. W., and D. Atlas, 2002: On the separation of tropical convective and stratiform rains. J. Appl. Meteor., 41, 188-195.

_ Tropical continental and maritime storms. J. Appl. Meteor. Climatol., 46, 1777-1791.

Viltard, N., C. Kummerow, W. S. Olson, and Y. Hong, 2000: Combined use of radar and radiometer of TRMM to estimate the influence of drop size distribution on rain retrievals. J. Appl. Meteor., 39, 2103-2114.

Waldvogel, A., 1974: The $N_{0}$ jump of raindrop spectra. J. Atmos. Sci., 31, 1067-1078.
Williams, C. R., W. L. Ecklund, and K. S. Gage, 1995: Classification of precipitating clouds in the tropic using $915-\mathrm{MHz}$ wind profilers. J. Atmos. Oceanic Technol., 12, 996-1012.

_ - A. Kruger, K. S. Gage, A. Tokay, R. Cifelli, W. F. Krajewski, and C. Kummerow, 2000: Comparison of simultaneous rain drop size distributions estimated from two surface disdrometers and a UHF profiler. Geophys. Res. Lett., 27, 1763-1766.

Willis, P. T., and P. Tattelman, 1989: Drop size distribution associated with intense rainfall. J. Appl. Meteor., 28, 3-15.

Yuter, S. E., and R. A. Houze Jr., 1997: Measurements of raindrop size distribution over the Pacific warm pool and implementation for $Z-R$ relations. J. Appl. Meteor., 36, 847-867. 